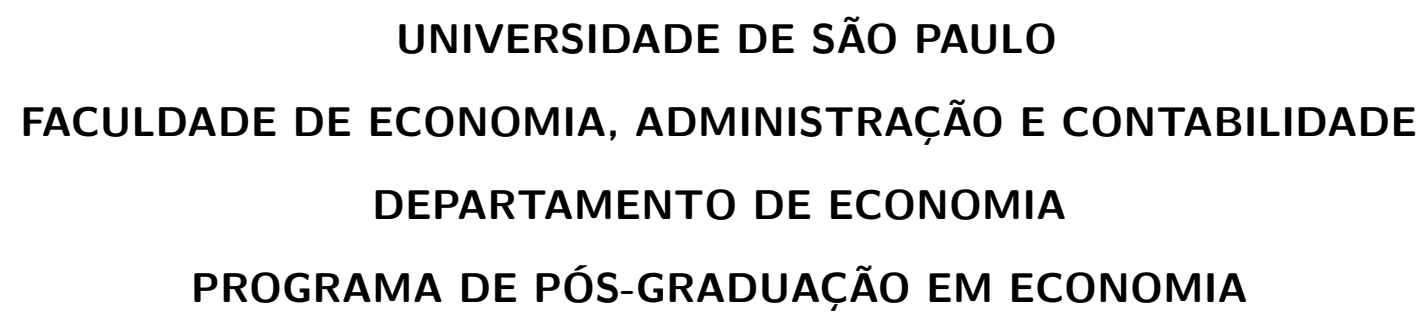

\title{
Leilão Aberto Versus Leilão Selado: Evidência com Dados Brasileiros de Compras
}

\section{Governamentais}

\author{
Anderson Cardoso Pinto de Souza \\ Orientador: Prof. Dr. Rafael Coutinho Costa Lima
}

São Paulo - Brasil 
Prof. Dr. Marco Antonio Zago

Reitor da Universidade de São Paulo

Prof. Dr. Adalberto Américo Fischmann

Diretor da Faculdade de Economia, Administração e Contabilidade

Prof. Dr. Hélio Nogueira da Cruz

Chefe do Departamento de Economia

Prof. Dr. Márcio Issao Nakane

Coordenador do Programa de Pós-Graduação em Economia 


\title{
Leilão Aberto Versus Leilão Selado: Evidência com Dados Brasileiros de Compras
}

\section{Governamentais}

\author{
Dissertação apresentada ao Programa de \\ Pós-Graduação em Economia do Depar- \\ tamento de Economia da Faculdade de \\ Economia, Administração e Contabilidade \\ da Universidade de São Paulo como requisito \\ parcial para a obtenção do título de Mestre \\ em Ciências.
}

Orientador: Prof. Dr. Rafael Coutinho Costa Lima

Versão Corrigida

(versão original disponível na Faculdade de Economia, Administração e Contabilidade)

São Paulo - Brasil

2015 
FICHA CATALOGRÁFICA

Elaborada pela Seção de Processamento Técnico do SBD/FEA/USP

Souza, Anderson Cardoso Pinto de

Leilão aberto versus leilão selado: evidência com dados brasileiros de compras governamentais / Anderson Cardoso Pinto de Souza. -São Paulo, 2015.

$80 \mathrm{p}$.

Dissertação (Mestrado) - Universidade de São Paulo, 2015.

Orientador: Rafael Coutinho Costa Lima.

1. Organização industrial 2. Econometria 3. Leilão 4. Licitação I. Universidade de São Paulo. Faculdade de Economia, Administração e Contabilidade. II. Título.

$$
\text { CDD - } 338.6
$$




\section{Agradecimentos}

Primeiramente, agradeço a Deus e aos meus pais por tudo que fizeram e fazem por mim. Tudo o que sou e faço, tudo o que quero ser e fazer dependem, em alguma medida, do que me ensinaram ou me ensinarão ao longo da minha vida, e por isso, lhes serei eternamente grato.

Agradeço a meu orientador, Rafael Coutinho Costa Lima, pela grande atenção e paciência que disponibilizou no decorrer deste trabalho. Menciono também o Prof. Dr. Ricardo Avelino que disponibilizou a base de dados desse trabalho num formato acessível a este mestrando.

Agradeço também à Prof. ${ }^{a}$ Dra. Nathalie Sanches e ao Prof. Dr. Fábio Sanches pelas discussões e explicações sobre leilões e algoritmos extremamente frutuosas e sem as quais este trabalho não existiria.

Envio também os meus agradecimentos aos meus colegas de turma do IPE-USP que me ajudaram durante todo o caminho, esclarecendo dúvidas sobre as matérias, sobre as listas de exercícios, sobre as aulas, sobre os softwares, sobre economia, sobre a vida; em especial Danilo de Paula Souza, Michael França e Leonardo Rosa. Também agradeço a Thomaz Gemignani, Eduardo Astorino e Eduardo Alonso que ouviram muitas das minhas ideias e angustias nessa etapa da minha vida. 

"A pior forma de desigualdade é tentar fazer duas coisas diferentes iguais." 



\section{Resumo}

Nós comparamos o leilão aberto e o leilão selado utilizados para compras públicas na Bolsa Eletrônica de Compras (BEC) do Estado de São Paulo usando dados das transações de açúcar refinado entre 2008 e 2011. O leilão selado gera uma economia para o Estado de aproximadamente $3 \%$ em relação ao leilão aberto. Sob a ótica do paradigma de valores privados independentes, nós adotamos um modelo com licitantes assimétricos e aversão ao risco. Ao recuperar a propensão a pagar dos participantes com econometria estrutural, descobrimos que estas hipóteses se encaixam razoavelmente bem aos leilões, ainda que não possamos descartar conluio ou comportamentos gerados por leilões online.

Palavras-chaves: Organização Industrial, Econometria, Leilão, Licitação 



\section{Abstract}

We compared the open and the sealed bid auctions used for procurement transaction at the electronic platform Bolsa Eletrônica de Compras (BEC) of São Paulo state using data from refined sugar purchases between 2008 and 2011. The sealed bid generates lower prices in about $3 \%$ compared to the open auction. Under the independent private values paradigm, we adopted asymmetric bidders and risk aversion. We recover with structural econometrics the cumulative distribution functions of cost of potential bidders and we found evidence we can fit reasonably well our data, although we cannot reject collusion or behaviors generated by online auctions.

Key-words: Industrial Organization, Econometrics, Auction, Procurement Auction 



\section{Lista de ilustrações}

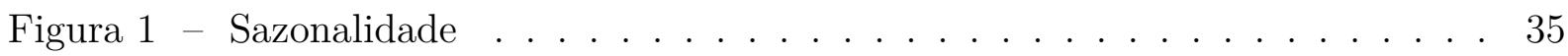

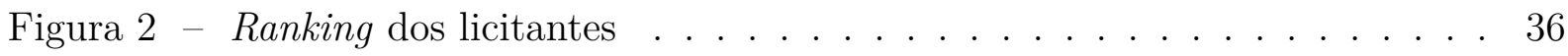

Figura 3 - Densidade de Micro e Pequenas empresas versus outras empresas . . . 38

Figura 4 - Exemplos de comportamento dos licitantes . . . . . . . . . . . . . . 39

Figura 5 - Competição em alguns meses com base na frequência de vitórias dos licitantes em meses anteriores . . . . . . . . . . . . . . . . 40

Figura 6 - Histograma sobre especialização no formato de licitação . . . . . . . . . 41

Figura 7 - Função distribuição acumulada estimada para cada tipo de licitante . . 53

Figura 8 - Função densidade estimada para cada tipo de licitante . . . . . . . . . 54

Figura 9 - Função melhor resposta de cada tipo de licitante . . . . . . . . . 56 



\section{Lista de tabelas}

Tabela 1 - Estatísticas descritivas por formato de licitação e por ano . . . . . . . 37

Tabela 2 - Estatísticas descritivas das medidas de licitantes potenciais . . . . . . . 42

Tabela 3 - Comparação de preço entre formatos de licitação . . . . . . . . . . . . 45

Tabela 4 - Propensity score sobre formato de licitação . . . . . . . . . . . . 46

Tabela 5 - Efeito do formato de licitação sobre $\ln$ (Preço) por Propensity Score Matching .......................... 47

Tabela 6 - Parâmetros das funções de custo estimados por máximo a verossimilhança 52

Tabela 7 - Resultados de Predição do Modelo e da Simulação . . . . . . . . . . . 58

Tabela 8 - Formato de licitação por município . . . . . . . . . . . . . 67

Tabela 9 - Comparação dos controles após o Matching . . . . . . . . . . . . 69

Tabela 10 - Agregação dos municípios para estimação estrutural . . . . . . . . . . . 71

Tabela 11 - Comparação de preço entre formatos de licitação - Nova classificação dos licitantes . . . . . . . . . . . . . . . . . . 74

Tabela 12 - Resultados de Predição do Modelo e da Simulação - Nova classificação de licitantes . . . . . . . . . . . . . . . . . . . . 75

Tabela 13 - Estatísticas descritivas por formato de licitação e por ano - Detergente 78

Tabela 14 - Comparação de preço entre formatos de licitação - Detergente .... 79

Tabela 15 - Efeito do formato de licitação sobre $\ln ($ Preço) por Propensity Score Matching-Detergente . . . . . . . . . . . 80

Tabela 16 - Resultados de Predição do Modelo e da Simulação - Detergente ... 81 



\section{Sumário}

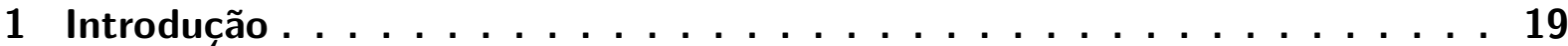

2 Revisão da Literatura . . . . . . . . . . . . . . . . . 23

3 Ambiente Institucional . . . . . . . . . . . . . . . . . . . . . 27

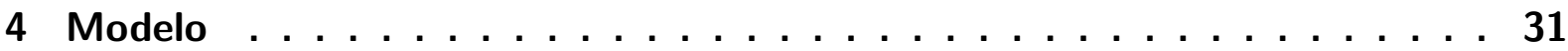

5 Dados .......................... 35

6 Análise Empírica $\ldots \ldots \ldots \ldots \ldots$. . . . . . . . . . . 43

6.1 Análise Exploratória . . . . . . . . . . . . . . . . . . 43

6.2 Análise Estrutural . . . . . . . . . . . . . . . . . . 48

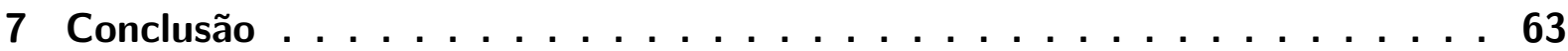

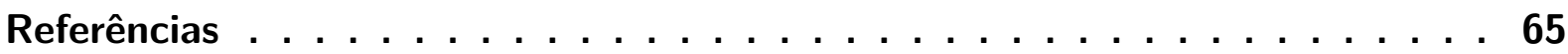

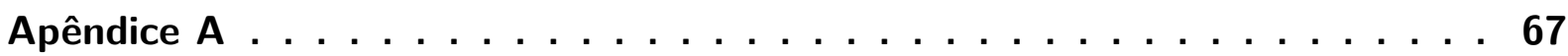

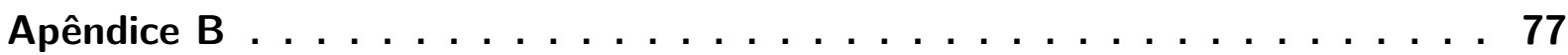





\section{Introdução}

Leilões são instituições de mercado com regras de alocação de recursos e formação de preços bem definidas. ${ }^{1}$ Estão largamente difundidos na sociedade e pode-se vender e comprar uma grande variedade de bens em leilões presenciais ou digitais, por exemplo, em sites como eBay e Mercado Livre. Governos também possuem grandes interesses em leilões, pois usam esse mecanismo para a compra de suas mercadorias, usualmente chamadas de licitações. Também utilizam leilões na venda de direitos de concessão de exploração de recursos, como no caso das ondas de transmissão de telefone e internet.

Há muitos formatos de leilões, pois determinados arranjos podem ser melhores para maximizar a receita do vendedor, privilegiar um determinado grupo ou evitar possíveis formas de conluio entre os participantes.

Sob o paradigma de valores privados independentes, o Teorema de Equivalência de Receita diz que qualquer forma de leilão gera a mesma receita esperada para o vendedor do bem, se os participantes forem simétricos e neutros ao risco. Ausente alguma dessas condições, é possível que algum formato seja mais vantajoso para o vendedor do bem.

Do ponto de vista empírico, a comparação entre formas de leilão é muito difícil e há poucos trabalhos que fazem esse tipo de comparação e nenhum trabalho encontrado utiliza dados brasileiros. Uma das principais razões está relacionada à dificuldade de se encontrar os mesmos bens vendidos sob formatos diferentes de leilão.

Neste trabalho nos propomos a fazer uma comparação de formatos de leilão usando os processos de compra da Bolsa Eletrônica de Compras (BEC) do Estado de São Paulo. Com os dados da BEC, nós podemos superar as dificuldades em comparar formatos diferentes de leilões, pois as compras são feitas por diferentes modalidades e os bens transacionados possuem uma descrição minuciosa. Para nossa comparação, utilizamos os dados de compra de açúcar refinado pelas diversas unidades públicas do Estado de São Paulo entre 2008 e 2011. Também colocamos no Apêndice B resultados que obtivemos com compras de detergentes feitas no mesmo período.

1 Definição baseada em McAfee e McMillan (1987, p.701) 
As modalidades comparadas foram o Convite e a Dispensa de Licitação. O Convite é um leilão selado cujo vencedor é aquele que oferta o menor preço. A Dispensa de Licitação é um leilão aberto reverso onde os participantes oferecem lances cada vez menores até que nenhum licitante esteja disposto a dar um novo lance.

Nossos exercícios empíricos encontram que o leilão selado gera um preço ao redor de $3 \%$ menor que o leilão aberto. Desta forma, nós encontramos uma clara recomendação de política para o Estado economizar recursos públicos.

Encontrada a diferença de preço entre os formatos de leilão na BEC, nos dirigimos para explicar as suas causas. Para explicar os motivos dessa diferença, recuperamos a disposição a vender dos participantes a partir dos dados observados. Com a disposição a vender dos participantes, podemos verificar se nosso modelo teórico é capaz de comportar essa diferença entre os formatos.

Primeiramente, utilizamos os dados das licitações abertas para estimarmos a função distribuição acumulada de custo de cada participante, pois esta representa sua propensão a vender. Em seguida, utilizamos essa estimativa para simular como os licitantes se comportariam numa licitação selada. Para o formato selado, da mesma forma que em Athey, Levin e Seira (2011), nossas previsões são fora da amostra em 2 sentidos: são previsões para uma amostra diferente da qual foram estimadas; e também de um formato de licitação diferente da qual foram estimadas. Por fim, adotamos alguns valores de aversão ao risco para complementar a simulação.

Sob a ótica do paradigma de valores privados independentes, nós encontramos que um modelo com assimetria representando os Grandes, Médios e Pequenos competidores na BEC e com aversão ao risco, se adequam muito bem aos dados, ainda que não possamos descartar conluio ou outros comportamentos gerados por leilões eletrônicos.

O trabalho está organizado como se segue. O capítulo 1 é composto dessa introdução. O capítulo 2 faz a revisão da literatura citando os principais resultados teóricos e trabalhos empíricos de comparação de formatos de leilão. O capítulo 3 traz a descrição dos formatos dos leilões usados na BEC. O capítulo 4 explica o modelo teórico usado no trabalho. O 
capítulo 5 traz a descrição dos dados que usamos. O capítulo 6 mostra os resultados da comparação entre os formatos de leilão. O capítulo 7 faz o apanhado das conclusões do trabalho. O Apêndice A mostra as tabelas que foram omitidas do texto principal. Por fim, o Apêndice B mostra os resultados dos nossos exercícios empíricos para outro bem transacionado na BEC. 



\section{Revisão da Literatura}

Leilões determinam o preço de venda e a alocação de um bem pertencente a um dado ofertante, entre vários possíveis demandantes. Possuem uma estreita relação com licitações, pois estas também possuem regras que determinam o preço de compra e o ofertante vencedor, onde o Estado é o único demandante. Desta forma, também pode-se dizer que a licitação é um leilão reverso. A literatura se concentrou em estudar os resultados concernentes às diferentes formas de leilões, contudo são facilmente adaptáveis para licitações. Por este motivo, anunciaremos os resultados da literatura como apresentados por seus autores e faremos um comentário de seus resultados em termos de licitações quando pertinente.

Leilões são modelados como jogos de informação incompleta onde o tipo de estrutura de informação, as estruturas de preferências dos participantes e o formato do leilão determinam o entendimento do jogo.

Usa-se uma estrutura de valor privado quando os compradores conhecem sua própria propensão a pagar e desconhecem a propensão a pagar dos demais. A distribuição de probabilidade da propensão a pagar de todos os participantes do leilão é de conhecimento comum. Quando a propensão a pagar dos participantes do leilão é sorteada de maneira independente, temos uma estrutura de valor privado independente, doravante IPV. Neste caso, quando a propensão a pagar dos participantes provém da mesma distribuição de probabilidade, temos uma estrutura de informação IPV com simetria. Quando a propensão a pagar é originada de duas ou mais distribuições, temos uma estrutura IPV com assimetria. Em licitações, a propensão a pagar é substituída pelo custo de produção do item em questão.

Com relação às estruturas de preferências, os participantes costumam ser neutros ao risco ou avessos ao risco. Contudo, essas estruturas não afetam todos os formatos de leilão da mesma forma. Por exemplo, para o leilão aberto de preço ascendente (leilão Inglês) a estrutura de preferências é irrelevante, enquanto é bastante relevante para o leilão selado. 
A comparação de diferentes formatos de leilão é antiga na literatura. Vickrey (1961) mostrou que usando uma estrutura de IPV simétrica com participantes neutros ao risco o leilão aberto de preço ascendente e o leilão Holandês resultam na mesma receita esperada ao ofertante do bem. Em seus resultados o autor assume uma distribuição uniforme de propensão a pagar. Vale ressaltar também que o leilão Holandês é estrategicamente equivalente ao leilão selado.

Riley e Samuelson (1981) generalizam o resultado de Vickrey (1961) que passou a ser conhecido como Teorema (ou Princípio) de equivalência de receita. Sob uma estrutura de IPV com simetria e com participantes neutros ao risco, qualquer estrutura de leilão gera a mesma receita esperada para o ofertante do bem. No mesmo artigo, os autores mostram que sob aversão ao risco, a receita esperada em leilões selados de primeiro preço é maior que a dos leilões abertos de preço ascendente. Para licitações, o resultado acima implica que qualquer formato de licitação gera o mesmo custo para o Estado. Sob aversão ao risco dos licitantes, a licitação selada gera um custo menor ao Estado.

Milgrom e Weber (1982) mostram que quando há alguma correlação entre a propensão a pagar dos compradores, leilões de preço ascendente geram uma receita maior que leilões selados de primeiro preço. ${ }^{1}$

Maskin e Riley (2000) comparam os formatos do leilão aberto e o leilão selado em um modelo de IPV com assimetria. Em um contexto com dois tipos de participantes, os autores derivam seus resultados impondo que a distribuição de propensão a pagar do participante "forte" domina estocasticamente a do participante "fraco". Neste contexto, é possível que tanto o formato aberto quanto o selado seja mais vantajoso para o ofertante do bem em termos de receita esperada, a depender das funções de distribuição da propensão a pagar dos participantes. A relação de dominância estocástica afetaria somente quão agressivos serão os participantes no leilão. Em resumo, isso nos mostra que sob assimetria, não é possível dizer qual leilão ou licitação é mais vantajoso. Este resultado é particularmente importante neste trabalho, pois no capítulo 4 assumiremos assimetria em nosso modelo,

1 O conjunto de hipóteses usado pelos autores é bastante geral e engloba o IPV como caso particular. No presente trabalho, vamos nos restringir ao IPV. 
mas não imporemos nenhuma forma de dominância estocástica.

Do ponto de vista empírico, é difícil comparar formatos de leilão, pois são poucos os bens que são vendidos em mais de um formato. Por esta razão, a literatura empírica de comparação de formatos é relativamente pequena e muito dela se ateve à mesma fonte de dados: United States Forest Service. Através deste órgão, o governo americano concede o direito de extração de madeira através de um leilão. Algumas regiões usam mais de um formato de leilão, o que possibilita a comparação. Mead (1967) usa esses dados de venda de madeira da United States Forest Service e encontra, através de mínimos quadrados ordinários, que leilões selados de primeiro preço resultam em preços maiores que os leilões de preço ascendente. Hansen (1985) argumenta que mínimos quadrados ordinários não é o procedimento adequado para estes dados. O autor propõe um modelo de equações simultâneas que leve em conta a seleção dos participantes entre os formatos. Usando esta metodologia, o autor conclui que não há diferenças de receita entre os dois formatos de leilões.

Alguns autores tem usado a abordagem de econometria estrutural para estudar leilões, literatura iniciada com Paarsch (1992). A abordagem estrutural pode ser usada para recuperar a propensão a pagar dos participantes que não é observável. Utilizando variáveis observáveis do leilão, conhecendo-se a estrutura de informação, as preferências dos participantes e o formato do leilão, é possível conhecer as melhores respostas dos agentes que resultam num equilíbrio de Nash Bayesiano e aproveitar-se desta "estrutura" para recuperar as informações não observáveis. Como leilões possuem regras bem definidas, a aplicação das estratégias na identificação das avaliações privadas surge de forma imediata.

Com o arcabouço estrutural, Brendstrup e Paarsch (2006), fazem uma comparação de formatos de leilão sob IPV assimétrico com dados de um mercado de peixe em Grenå, Dinamarca. Primeiramente, os autores propõem um estimador para recuperar a função distribuição dos participantes de um leilão aberto sob as hipóteses acima. A seguir, obtêm a estimativa da função distribuição da propensão a pagar dos participantes e simulam como seria se os participantes comprassem peixe via um leilão holandês que também é usado em outras cidades da Dinamarca. Os autores encontram que o leilão inglês resulta 
num preço maior para os vendedores do que o leilão holandês.

Athey, Levin e Seira (2011) também utilizam dados da United States Forest Service e comparam o leilão aberto e o leilão selado. Os autores combinam entrada e assimetria em seu modelo. Antes de participar do leilão, o participante deve pagar um custo para descobrir o quanto está disposto a pagar pela coleta da madeira. O modelo inclui dois tipos de participantes: grandes e pequenos. Os primeiros são representados por firmas com maquinofatura adequada e os pequenos são aqueles que não a possuem. Na análise empírica, os autores encontram que o leilão selado gera uma receita para o governo em torno de 10\% maior numa das localidades estudadas. A estimação da função de distribuição da propensão a pagar dos participantes é feita através dos dados do leilão selado. Sob competição, a simulação para o leilão aberto resulta em valores superiores aos observados, indicando que pode haver conluio no leilão aberto para pagar um preço menor ao governo. 


\section{Ambiente Institucional}

A regulação das licitações no Brasil é feita pela Lei nº 8.666/1993. Ela refere-se a todas as entidades públicas subordinadas direta ou indiretamente à União, Estados e Munícipios. A lei refere-se a licitações pertinentes a obras, serviços, compras, alienações e locações das entidades públicas.

No Estado de São Paulo, uma parte das licitações é feita por meio eletrônico. Os órgãos públicos do Estado de São Paulo (Penitenciárias, Hospitais, Repartições administrativas, etc.) podem fazer sua requisição de compras através da BEC (Bolsa Eletrônica de Compras). Muitos tipos de materiais são comprados, tais como: remédios, alimentos, material hidráulico, material de escritório, etc. Os editais e resultados de cada licitação podem ser vistos através do próprio site da BEC.

Cada bem transacionado pela BEC possui normas técnicas altamente precisas, por isso, bens ofertados que não satisfaçam tais normas podem ser desclassificados do processo de licitação. A marca do produto deve ser informada no processo de licitação, mas é inócua para decidir o vencedor.

Um licitante deve estar inscrito no cadastro de fornecedores do Estado de São Paulo e também deve cadastrar quais produtos está apto a fornecer.

$\mathrm{Na}$ BEC há três modalidades possíveis de compras de materiais pelas Unidades Governamentais: Dispensa de Licitação, Convite e Pregão Eletrônico. Em todas as modalidades, os participantes podem dar lances com 4 quatro casas decimais e há um preço de reserva calculado pela BEC não divulgado aos licitantes. A identidade dos demais licitantes também é desconhecida aos participantes da licitação até a determinação do vencedor.

Em 2014, na modalidade Dispensa de Licitação foram negociados mais de $\mathrm{R} \$ 21$ milhões em itens comprados, na modalidade Convite quase $\mathrm{R} \$ 200$ milhões e na modalidade Pregão mais de $\mathrm{R} \$ 11$ bilhões foram negociados. ${ }^{1}$

Na modalidade Dispensa de Licitação são transacionados bens cujo valor total é de

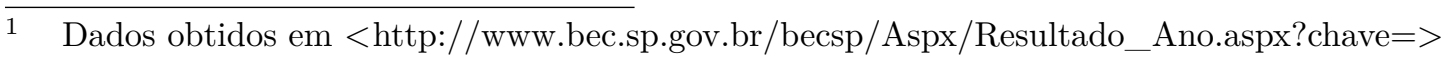


$\mathrm{R} \$ 8.000$ ou menos. ${ }^{2}$ Trata-se de um leilão aberto reverso, onde os licitantes submetem preços de venda do bem cada vez menores numa plataforma online. Os participantes podem submeter lances desde o período de início até o período de término previsto do edital. Este intervalo costuma ser de minutos. A plataforma online empregará uma prorrogação automática de 2 minutos enquanto houver lances após o horário limite do edital. Caso algum licitante submeta um lance superior ao valor de referência da BEC, o sistema indicará ao licitante que seu lance foi inválido. O licitante não sabe ao certo qual o menor preço ofertado dentro desta modalidade; sabe apenas se está vencendo ou perdendo a transação. O decréscimo mínimo é de $1 \%$ do menor valor da transação até o momento do lance. Após a determinação do vencedor, a identidade dos participantes e seus lances se tornam públicas.

A modalidade Convite é uma licitação selada de menor preço de valor limite de $\mathrm{R} \$$ 80.000. Os licitantes devem submeter somente um lance de acordo com o período estipulado pelo edital que costuma ser medido em dias. Ao fim do prazo, o licitante que deu o menor lance é declarado o vencedor da licitação e a identidade dos participantes e seus lances se tornam públicas.

O Pregão Eletrônico é um processo mais complexo que os anteriores voltado para qualquer valor, mas predominantemente para valores altos. Os licitantes devem enviar uma proposta numa fase classificatória, seguida de um leilão aberto reverso e depois de uma barganha com um representante do Estado. Esta modalidade está fora do escopo desse trabalho devido à sua complexidade.

O processo de uma licitação é descrito a seguir. As Unidades Governamentais fazem a requisição de um bem e escolhem o formato de licitação e a enviam para a BEC que publicará o edital. As empresas cadastradas na BEC são notificadas de algum edital através de sua plataforma eletrônica de acordo com suas linhas de fornecimento. De acordo com os prazos e características da licitação, os potenciais licitantes podem escolher se participam ou não do edital proposto.

Neste trabalho, vamos comparar os formatos da modalidade Dispensa de Licitação

$\overline{2}$ O valor limite é de $\mathrm{R} \$ 16.000$ para sociedades de economia mista. 
(leilão aberto reverso) e Convite (licitação selada) para o açúcar refinado vendidos em pacotes de $1 \mathrm{Kg}$ entre janeiro de 2008 e junho de $2011 .^{3}$ Nestes 42 meses foram transacionados mais de $R \$ 1$ milhão, somadas as 2 modalidades. Iremos nos restringir às compras de valor total menores de $\mathrm{R} \$ 8.000$ para fazermos uma comparação adequada entre as duas modalidades, pois elas possuem limites de preço diferentes.

3 A descrição detalhada do bem pode ser vista a seguir exatamente como se encontra no site da BEC: Cód. item: 35459 ACUCAR; OBTIDO DA CANA DE ACUCAR,REFINADO; COM ASPECTO COR,CHEIRO PROPRIOS,SABOR DOCE; COM TEOR DE SACAROSE MINIMO DE 99\%P/P E UMIDADE MAXIMA DE 0,3\%P/P; SEM FERMENTACAO, ISENTO DE SUJIDADES, PARASITAS, MATERIAIS TERROSOS E DETRITOS ANIMAIS OU VEGETAIS; ACONDICIONADO EM PLASTICO ATOXICO, VALIDADE MINIMA DE 11 MESES A CONTAR DA DATA DE ENTREGA; E SUAS CONDICOES DEVERAO ESTAR DE ACORDO COM A NTA-52/53(DECRETO 12.486 DE 20/10/78) 



\section{Modelo}

A frequência de vitórias dos licitantes da BEC, a ser descrita no capítulo 5, nos leva a utilizar um modelo que inclua 3 tipos de licitantes: Grandes, Médios e Pequenos. Por isso, usaremos modelos de leilões com uma estrutura de IPV assimétrica adaptados para licitação, considerando tanto o formato aberto quanto o formato selado. ${ }^{1}$

Mais especificamente, consideramos uma licitação de um bem sem valor de reserva por parte do comprador e um número de $N$ licitantes (ofertantes) potenciais. Cada licitante $i$ possui um custo de produção $C$ entendido como uma variável aleatória. Tal custo provém de forma independente de uma função distribuição acumulada duas vezes diferenciável $F_{i}(c)$ com densidade $f_{i}(c)$ de suporte $[\underline{c}, \bar{c}]$. A função distribuição acumulada de cada potencial licitante é de conhecimento comum, bem como suas identidades, mas a realização $c_{i}$ é conhecida somente pelo licitante $i$.

As hipóteses adotadas acima são evidentemente aproximações da competição efetiva da BEC. Nos formatos eletrônicos de licitação considerado nesse trabalho, os competidores não conhecem as identidades nem o número de licitantes antes do fim das licitações. Como as informações sobre os vencedores das licitações são públicas, estamos assumindo que cada competidor forma expectativa ou infira o número e tipo de seus competidores através de licitações anteriores. Desta forma, estamos aproximando o modelo de leilões presenciais para os nossos leilões eletrônicos. ${ }^{2}$

Representaremos pelos índices 1, 2 e 3 as variáveis de interesse dos tipos de licitantes Grandes, Médios e Pequenos, respectivamente. Assim, $N_{1}, N_{2}$ e $N_{3}$ representam o número de potenciais licitantes de cada grupo e $F_{1}(c), F_{2}(c)$ e $F_{3}(c)$ a função distribuição acumulada de custo de cada grupo.

Na licitação aberta, os licitantes oferecem lances cada vez menores e a licitação se encerra quando nenhum dos participantes está disposto a oferecer um preço menor. Desta

1 Esta seção segue os modelos presentes em Athey, Levin e Seira (2011), Campo (2012), Brendstrup e Paarsch (2006) e Hubbard e Paarsch (2014).

2 No capítulo 5, descreveremos como usaremos os dados do histórico de licitações para construir nossa medida de licitantes potenciais. Na seção 6.2 mostraremos que esse modelo possui uma aproximação razoável dos dados. 
forma, declara-se vencedor aquele que fez a última oferta. Na licitação selada, os licitantes ofertam seu valor ocultamente dos demais e ao término da licitação, todas as ofertas são reveladas e o vencedor é aquele que ofereceu o menor lance.

Consideremos a licitação aberta ou leilão inglês reverso segundo o clock model de Milgrom e Weber (1982). Um preço de venda inicial é determinado fora ou dentro do suporte da distribuição e cai lentamente. Os licitantes saem da licitação quando o preço de venda fica menor que seu próprio custo $c_{i}$ até sobrar somente um licitante. Cada licitante deve escolher uma estratégia em função de seu custo $s_{i}\left(c_{i}\right)$ que maximiza sua chance de vencer. Assim, uma estratégia fracamente dominante para todos aqueles que não venceram é dar um lance $b_{i}=s_{i}\left(c_{i}\right)=c_{i}$.

Se colocarmos em ordem decrescente todos os custos sorteados dos $N$ participantes, podemos introduzir a seguinte relação usando a notação de estatísticas de ordem: $C_{(1: N)}>$ $C_{(2: N)}>\ldots>C_{(N-1: N)}>C_{(N: N)}$, onde $C_{(1: N)}$ é o maior custo sorteado entre os $N$ participantes potenciais e $C_{(N: N)}$ é o menor dos custos sorteados entre os $N$ participantes potenciais. O licitante vencedor é aquele que possui o menor custo, mas ganha com um lance de $B=C_{(N-1: N)}$ onde $C_{(N-1: N)}$ é o segundo menor custo entre os $N$ potenciais participantes.

Para a licitação selada, considere a função lucro do licitante $i$ :

$$
\begin{aligned}
\pi_{i} & =U_{i}\left(b_{i}-c_{i}\right) \operatorname{Pr}\left(\text { vencer } \mid b_{i}\right) \\
& =U_{i}\left(b_{i}-c_{i}\right) \operatorname{Pr}\left(b_{i} \leq b_{j}, \forall j \neq i\right) \\
& =U_{i}\left(b_{i}-c_{i}\right) \prod_{j \neq i} \operatorname{Pr}\left(b_{j} \geq b_{i}\right) \text { (por independência) } \\
& =U_{i}\left(b_{i}-c_{i}\right) \prod_{j \neq i} \operatorname{Pr}\left(s_{j}\left(C_{j}\right) \geq b_{i}\right) \text { (assumimos a ex } \\
& \text { crescente e contínua } \forall j) \\
& =U_{i}\left(b_{i}-c_{i}\right) \prod_{j \neq i} \operatorname{Pr}\left(C_{j} \geq s_{j}^{-1}\left(b_{i}\right)\right) \\
& =U_{i}\left(b_{i}-c_{i}\right) \prod_{j \neq i}\left(1-F_{j}\left(s_{j}^{-1}\left(b_{i}\right)\right)\right) \\
& =U_{i}\left(b_{i}-c_{i}\right) \prod_{j \neq i}\left(1-F_{j}\left(\phi_{j}\left(b_{i}\right)\right)\right)
\end{aligned}
$$$$
=U_{i}\left(b_{i}-c_{i}\right) \prod_{j \neq i} \operatorname{Pr}\left(s_{j}\left(C_{j}\right) \geq b_{i}\right) \text { (assumimos a existência de uma função } s_{i}\left(C_{i}\right)
$$ 
O problema do licitante $i$ é encontrar o lance $b_{i}$ que maximiza seu lucro descrito na equação 4.1:

$$
\max _{b_{i}} U_{i}\left(b_{i}-c_{i}\right) \prod_{j \neq i}\left(1-F_{j}\left(\phi_{j}\left(b_{i}\right)\right)\right)
$$

Depois de algumas transformações, a condição de primeira ordem do problema 4.2 pode ser escrita como:

$$
\begin{aligned}
1 & =\frac{U_{i}\left(b_{i}-c_{i}\right)}{U_{i}^{\prime}\left(b_{i}-c_{i}\right)} \sum_{j \neq i} \frac{f_{j}\left(s_{j}^{-1}\left(b_{i}\right)\right)}{1-F_{j}\left(s_{j}^{-1}\left(b_{i}\right)\right)} \frac{1}{s_{j}^{\prime}\left(s_{j}^{-1}\left(b_{i}\right)\right)} \\
& =\frac{U_{i}\left(b_{i}-\phi_{i}\left(b_{i}\right)\right)}{U_{i}^{\prime}\left(b_{i}-\phi_{i}\left(b_{i}\right)\right)} \sum_{j \neq i} \frac{f_{j}\left(\phi_{j}\left(b_{i}\right)\right)}{1-F_{j}\left(\phi_{j}\left(b_{i}\right)\right)} \phi_{j}^{\prime}\left(b_{i}\right)
\end{aligned}
$$

Adicionalmente à equação 4.3, também existem as condições iniciais:

$$
\phi_{i}(\bar{c})=\bar{c}, \forall i
$$

$$
\phi_{i}(\underline{b})=\underline{c}, \forall i \text { e para alguma constante } \underline{b} \in[\underline{c}, \bar{c}]
$$

A demonstração da existência de solução desse problema pode ser vista em Maskin e Riley (2003). ${ }^{3}$ Para a função utilidade, adotaremos uma $\mathrm{HARA}^{4}$ com forma funcional descrita pela função abaixo:

$$
U_{i}\left(b_{i}-c_{i}\right)=\gamma_{i}\left(b_{i}-c_{i}\right)^{\frac{1}{\gamma_{i}}} \quad b_{i}-c_{i} \geq 0, \quad \gamma_{i} \geq 1
$$

A função 4.6 possui algumas características interessantes para este trabalho. A primeira consiste em que podemos obter neutralidade ao risco fazendo $\gamma_{i}=1$. A segunda característica reside em que ela possui medida de aversão ao risco absoluta hiperbólica. Isto implica que a equação 4.6 é uma função utilidade de medida de aversão ao risco relativa constante segundo a medida de Arrow-Pratt igual a $\frac{\gamma_{i}-1}{\gamma_{i}}$. Em outras palavras, a equação 4.6 também é uma $\mathrm{CRRA}^{5}$. A terceira característica fica por conta da interpretação do parâmetro $\gamma_{i}$. Como poderá ser visto na equação 4.7 , caso $\gamma_{i}>1$ os participantes se

3 Bajari (2001) demonstra a existência e unicidade do equilíbrio para o caso específico de licitação com licitantes neutros ao risco.

$4 \quad$ Sigla de hyperbolic absolute risk aversion em inglês.

5 Sigla de constant relative risk aversion em inglês. 
comportam como se houvesse mais competidores do que existem na realidade.

Utilizando a forma funcional de 4.6, adotando apenas os três tipos de licitantes e substituindo $b_{i}$ por lances genéricos $b$, podemos reescrever a equação $4.3 \mathrm{em}$ forma de um sistema implícito de equações diferenciais nas funções $\phi_{1}, \phi_{2}$ e $\phi_{3}$ :

$$
\left\{\begin{array}{l}
1=\gamma_{1}\left(b-\phi_{1}(b)\right) \cdot\left(\left(N_{1}-1\right) \frac{f_{1}\left(\phi_{1}(b)\right) \phi_{1}^{\prime}(b)}{1-F_{1}\left(\phi_{1}(b)\right)}+N_{2} \frac{f_{2}\left(\phi_{2}(b)\right) \phi_{2}^{\prime}(b)}{1-F_{2}\left(\phi_{2}(b)\right)}+N_{3} \frac{f_{3}\left(\phi_{3}(b)\right) \phi_{3}^{\prime}(b)}{1-F_{3}\left(\phi_{3}(b)\right)}\right) \\
1=\gamma_{2}\left(b-\phi_{2}(b)\right) \cdot\left(N_{1} \frac{f_{1}\left(\phi_{1}(b)\right) \phi_{1}^{\prime}(b)}{1-F_{1}\left(\phi_{1}(b)\right)}+\left(N_{2}-1\right) \frac{f_{2}\left(\phi_{2}(b)\right) \phi_{2}^{\prime}(b)}{1-F_{2}\left(\phi_{2}(b)\right)}+N_{3} \frac{f_{3}\left(\phi_{3}(b)\right) \phi_{3}^{\prime}(b)}{1-F_{3}\left(\phi_{3}(b)\right)}\right) \\
1=\gamma_{3}\left(b-\phi_{3}(b)\right) \cdot\left(N_{1} \frac{f_{1}\left(\phi_{1}(b)\right) \phi_{1}^{\prime}(b)}{1-F_{1}\left(\phi_{1}(b)\right)}+N_{2} \frac{f_{2}\left(\phi_{2}(b)\right) \phi_{2}^{\prime}(b)}{1-F_{2}\left(\phi_{2}(b)\right)}+\left(N_{3}-1\right) \frac{f_{3}\left(\phi_{3}(b)\right) \phi_{3}^{\prime}(b)}{1-F_{3}\left(\phi_{3}(b)\right)}\right)
\end{array}\right.
$$

Onde as 6 condições de valor inicial são:

$$
\begin{gathered}
\phi_{m}(\bar{c})=\bar{c}, \quad m=1,2 \text { e } 3 \\
\phi_{m}(\underline{b})=\underline{c}, \quad m=1,2 \text { e } 3 \text { e para alguma constante } \underline{b} \in[\underline{c}, \bar{c}]
\end{gathered}
$$

O sistema 4.7 não possui solução analítica ${ }^{6}$ e como visto no capítulo 2 , não é possível saber qual dos formatos gera o menor custo para o comprador da mercadoria. Por isso, na seção 6.1 vamos comparar os formatos de licitação entre si e descobrir qual deles resulta no menor preço. Na seção 6.2 vamos estimar a função distribuição acumulada de custo de cada tipo de licitante utilizando os modelos deste capítulo e verificar se podemos replicar os mesmos padrões que se observam nos dados.

6 Veja Hubbard e Paarsch (2014) para uma discussão dos motivos técnicos. 


\section{Dados}

Utilizamos nesse trabalho compras de açúcar refinado por parte de várias unidades públicas do Estado de São Paulo. Para cada transação, possuímos um identificador único do licitante vencedor, o preço vendido, a quantidade vendida, a localização e a identificação da unidade governamental, data da venda e se a empresa vencedora é microempresa, empresa de pequeno porte ou outra. Nós não possuímos as informações dos licitantes que de fato participaram de cada licitação, mas utilizaremos os dados que dispomos para construir nossa medida de licitantes potenciais.

O primeiro aspecto a ser observado dos dados é a sazonalidade das licitações. Essa informação está resumida na Figura 1. A figura realça os meses de janeiro de cada ano, pois indicam uma queda bastante acentuada nas licitações de ambos os formatos em virtude das férias. Por este motivo, toda análise de comparação dos formatos de licitação é feita retirando os meses de janeiro da amostra.

Figura 1 - Sazonalidade

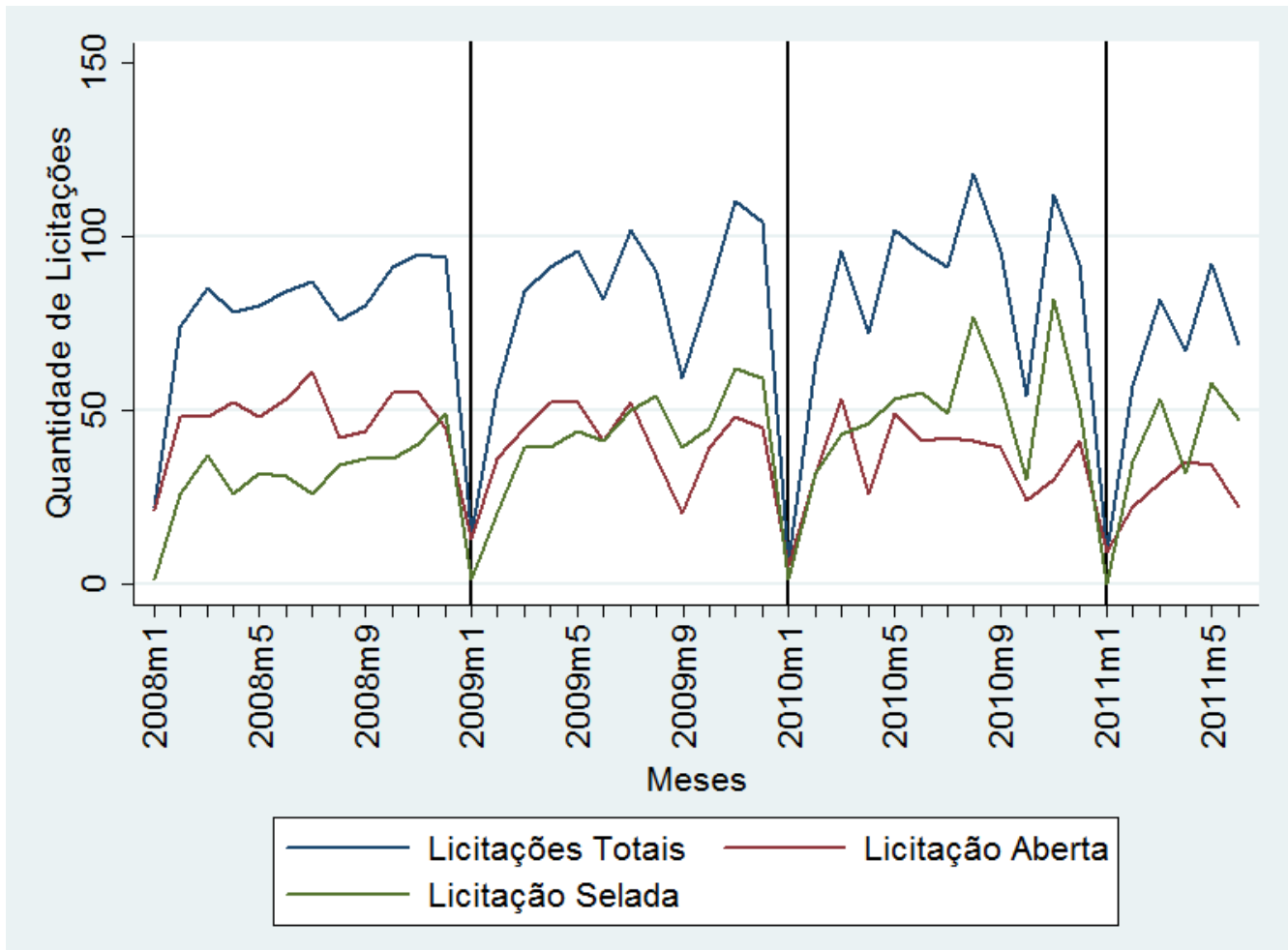

Fonte: BEC

Nota: Elaboração Própria

A Tabela 1 apresenta um resumo detalhado dos dados por modalidade de licitação. 
Figura 2 - Ranking dos licitantes

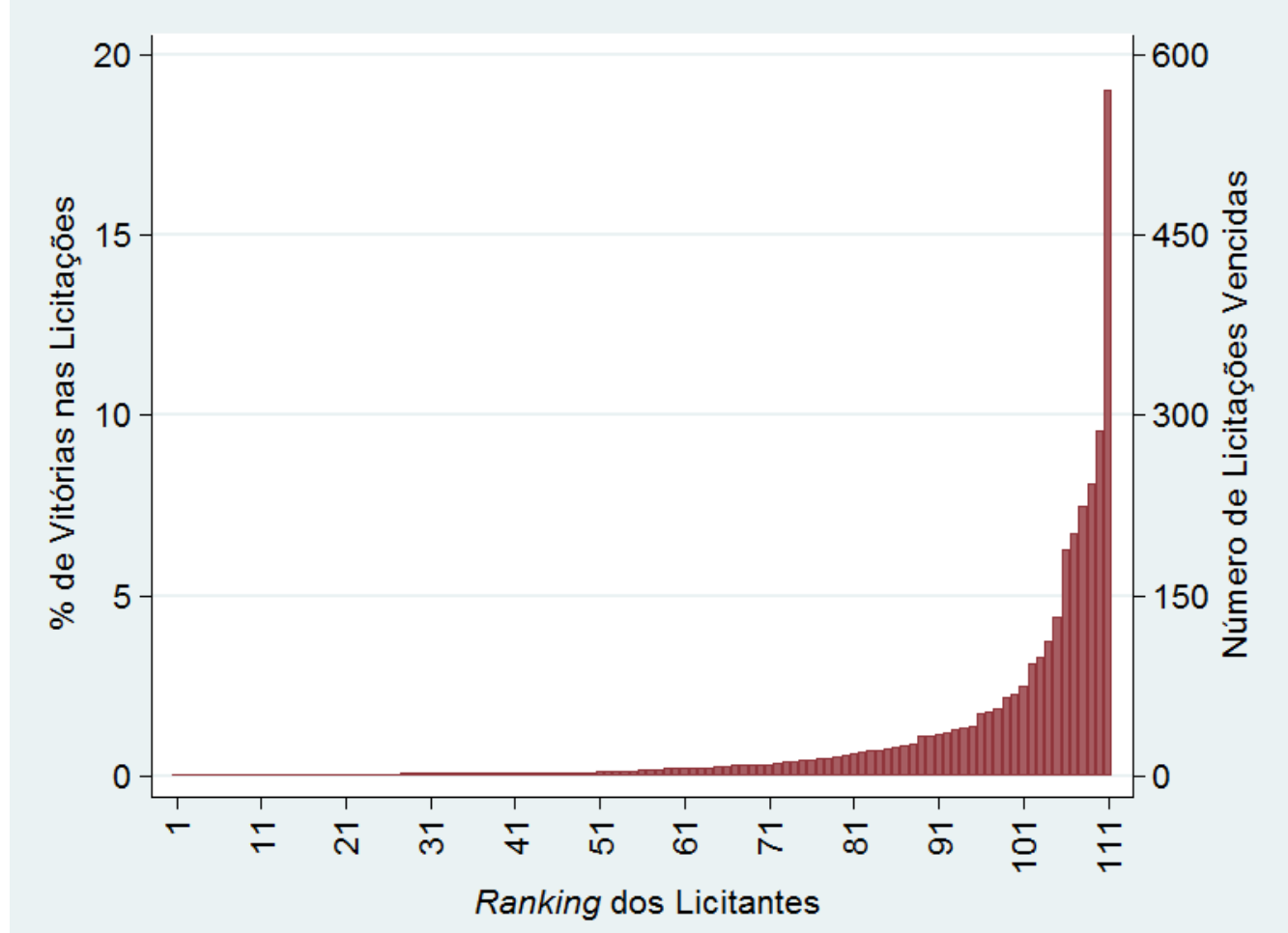

Fonte: BEC.

Nota: Elaboração Própria.

Primeiramente, nota-se que o preço de venda da licitação aberta é maior que o da licitação selada em todos os anos. A licitação selada possui, em média, uma quantidade maior e um valor total maior que a licitação aberta. Como as licitações possuem limites de preços diferentes ( $R \$ 8.000$ para aberta e $R \$ 80.000$ para a selada) era de se esperar que a licitação selada tivesse transações totais mais próximas de $\mathrm{R} \$ 8.000$.

Algumas cidades apresentam uma proporção parecida de cada formato (por exemplo, Bauru) enquanto outras não apresentam todos os tipos de licitações (por exemplo, Avaré e Bebedouro). Nota-se também que a cidade de São Paulo concentra quase $50 \%$ das licitações (esta informação se encontra na Tabela 8, no Apêndice A).

Nós identificamos 111 licitantes diferentes e os indicamos na Figura 2 pelo seu ranking, onde 1 indica o licitante que venceu menos vezes e 111 o que venceu mais vezes. A grande desproporção de vitórias entre os licitantes, nos leva a acreditar que a hipótese de assimetria é adequada para a nossa amostra, pois no caso simétrico, esperaríamos uma proporção mais homogênea de vitórias entre os licitantes. 


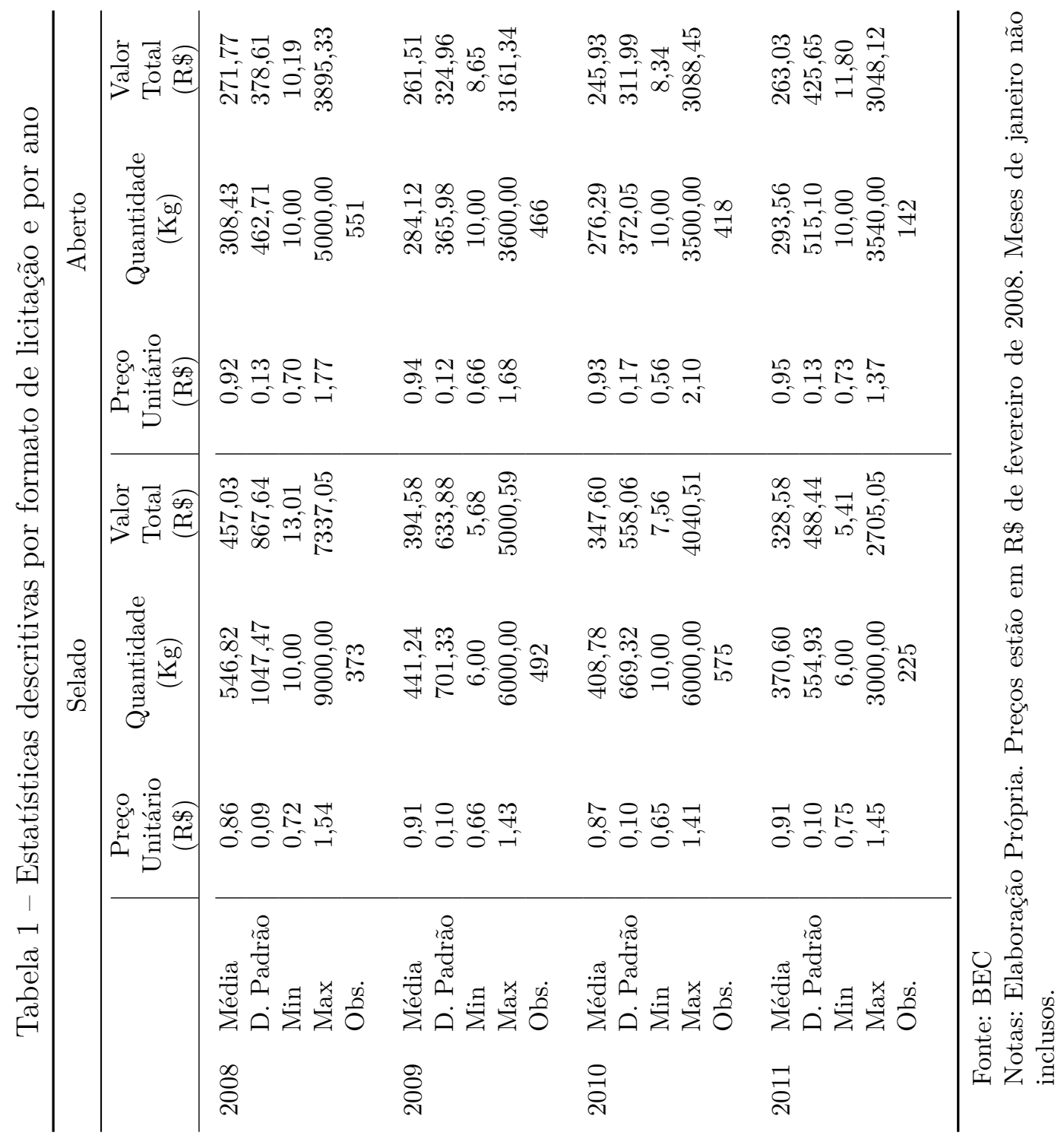


Figura 3 - Densidade de Micro e Pequenas empresas versus outras empresas

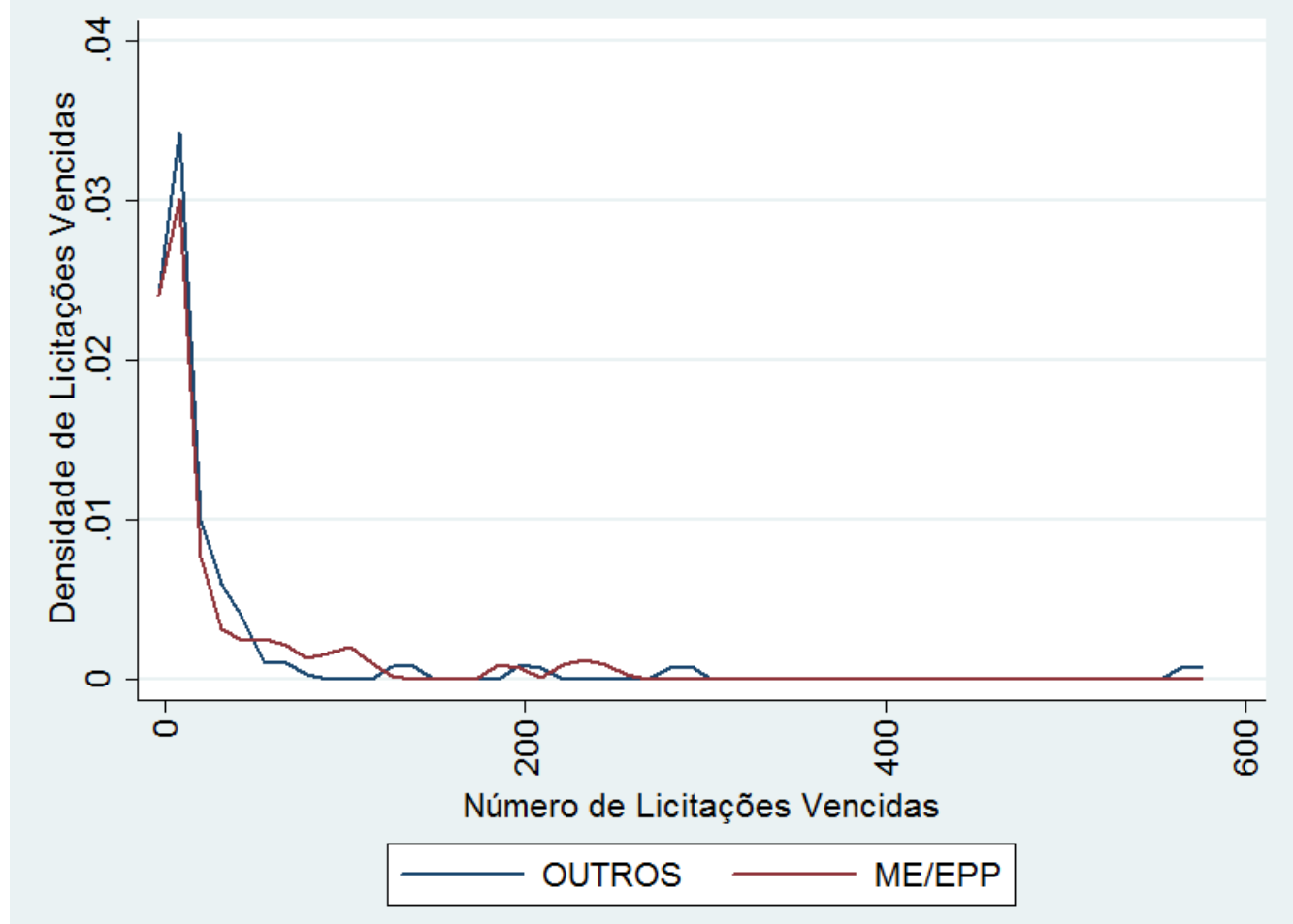

Fonte: BEC.

Nota: Elaboração Própria.

Uma possível forma de explicar essa diferença é pelo enquadramento jurídico das empresas, comparando Microempresas (ME) e empresas de pequeno porte (EPP) contra outros tipos de enquadramento. A Figura 3 compara essas formas de enquadramento jurídico e mostra que a frequência de vitória entres os diferentes enquadramentos é bastante parecida. Sendo assim, definiremos a assimetria de uma forma arbitrária usando as frequências de vitórias.

Desta forma, dividiremos os licitantes em três tipos diferentes com base em suas frequências de vitórias: Grandes, Médios e Pequenos. Contudo, para fazer essa divisão, não usaremos simplesmente a frequência de vitórias de cada licitante. Esta medida nos levaria a não contar possíveis desistências ou entradas de licitantes ao longo do período estudado. A Figura 4 mostra alguns exemplos do comportamento das vitórias dos licitantes. O licitante 111 vence alguma licitação em quase todos os períodos de tempo da amostra. O licitante 108 não vence nenhuma licitação a partir de 2009, o que pode ser facilmente interpretado como uma saída deste mercado. Por fim, o licitante 81, aparentemente, entra 
Figura 4 - Exemplos de comportamento dos licitantes

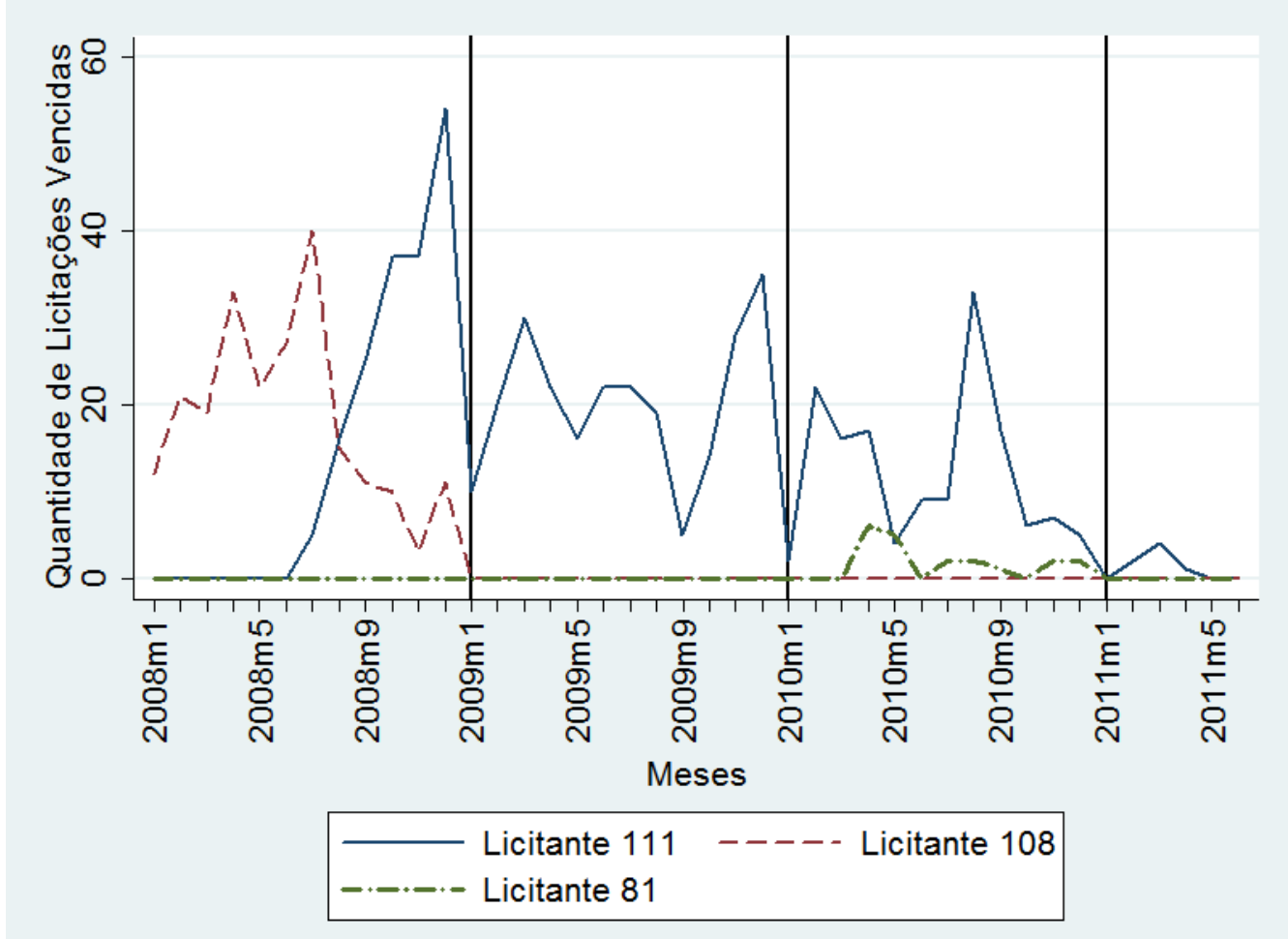

Fonte: BEC.

Nota: Elaboração Própria.

em 2010 no mercado e sai em 2011.

Como a informação da vitória dos licitantes é pública, é possível para todos os licitantes descobrirem os Grandes, Médios e Pequenos competidores através das informações provenientes de licitações prévias. Por isso, vamos construir nossa medida de licitantes potenciais para cada tipo, observando a proporção de vitórias dentro dos 5 meses anteriores ao mês da licitação disputada, excluindo o mês de janeiro. ${ }^{1}$ Neste período, aqueles que venceram $15 \%$ ou mais das licitações serão classificados de Grandes licitantes potenciais da licitação (identificados pelo índice 1), aqueles que ficaram entre 15\% e 5\% serão classificados de Médios licitantes potenciais (identificados pelo índice 2) e os que venceram $5 \%$ ou menos das licitações serão classificados como Pequenos licitantes potenciais (identificados pelo índice 3). ${ }^{2}$ A escolha destes limites favorece a classificação dos licitantes como Pequenos. Os

$1 \quad$ Nós testamos diferentes janelas para fazermos essa análise e não há mudanças significativas em termos dos resultados da seção 6.1 .

2 Se um licitante venceu licitações somente em um período inferior aos 5 meses (por exemplo, 3 meses) comparamos sua proporção de vitórias dentro deste período de vitórias (isto é, 3 meses). Este procedimento facilita identificar médios e grandes licitantes que não apareceram nos primeiros meses da amostra. 
Figura 5 - Competição em alguns meses com base na frequência de vitórias dos licitantes em meses anteriores
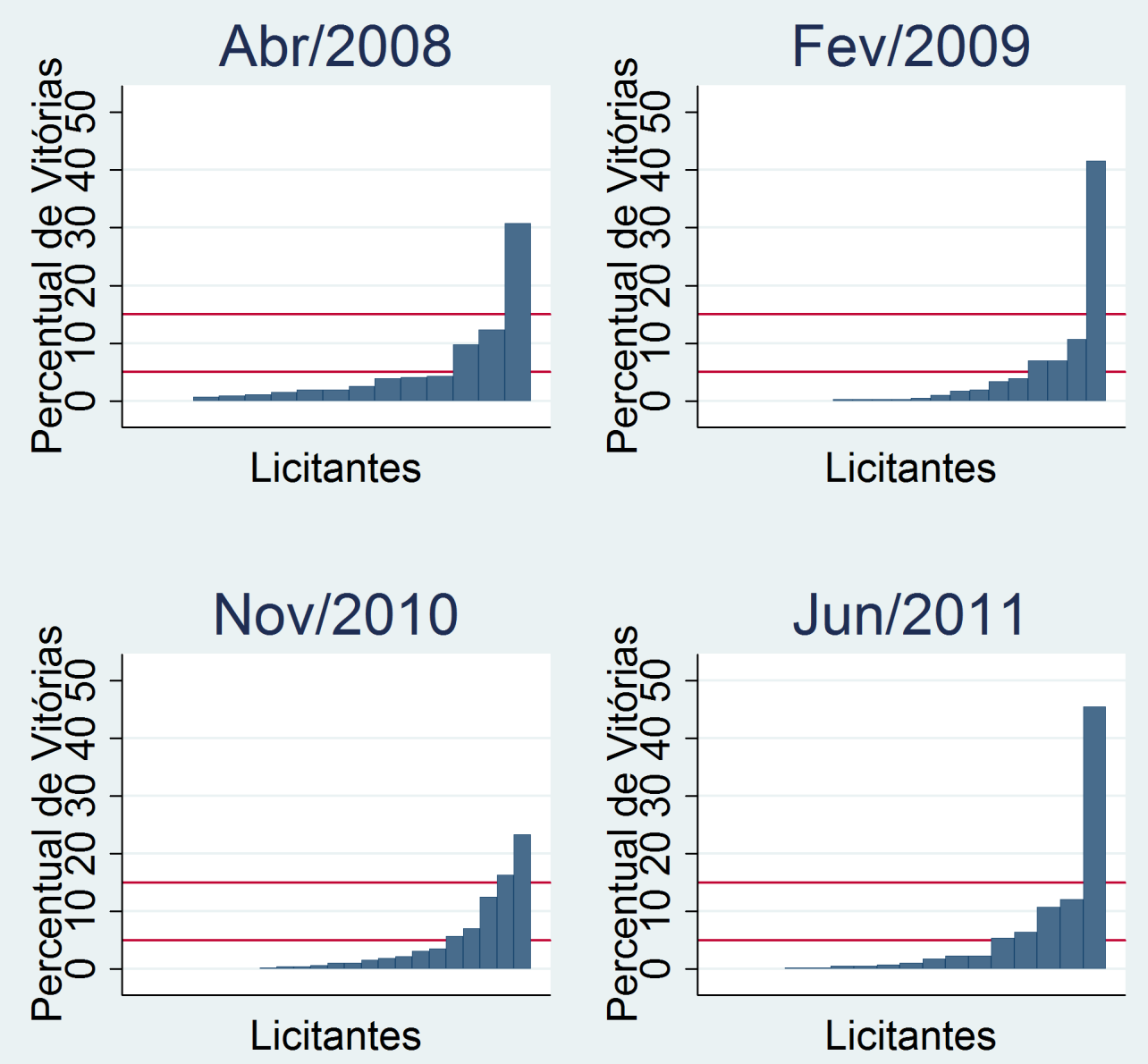

Fonte: BEC.

Nota: Elaboração Própria.

que não venceram nenhuma licitação no período de 5 meses anteriores, não são considerados como licitantes potenciais da licitação em questão. Dentro do primeiro mês de vitória de um licitante, ele é considerado como um pequeno licitante.

A Figura 5 mostra alguns exemplos da competição obtida pelo método acima em alguns meses da amostra. A figura indica com cada barra um licitante e sua proporção de vitória nos últimos 5 meses e os limites de $15 \%$ e $5 \%$ para definir os grupos. A Tabela 2 descreve em detalhes nossas medidas dos três tipos de licitantes para a nossa amostra.

Esta classificação possui a característica de que alguns licitantes possam mudar de classificação em determinados períodos. Em nossa visão, essas mudanças não são inconvenientes, pois refletem o custo de oportunidade dos licitantes em participar mais 
ativamente deste mercado em virtude de suas outras opções.

A nossa medida de licitantes potenciais assume que os licitantes participam de qualquer licitação independentemente do seu formato. Para verificar se os dados corroboram essa hipótese, construímos um indicador para cada licitante igual à fração de licitações abertas frente o total de licitações ganhas. Indicadores mais próximos de zero indicam especialização na licitação selada, enquanto indicadores próximos de 1 indicam especialização na licitação aberta. A Figura 6 mostra um histograma dessa medida para todos os licitantes e para aqueles que venceram acima de 10 licitações. A amostra total mostra uma grande concentração nas pontas do histograma, contudo, isso se deve a que muitos licitantes venceram poucas licitações e, por isso, de apenas um tipo. Quando se consideram somente aqueles que venceram mais de 10 licitações, nota-se que a frequência sobre as caudas se reduz drasticamente. Assim, não temos motivos para acreditar que os licitantes só participem de algum formato específico de licitação.

Figura 6 - Histograma sobre especialização no formato de licitação

\section{Todos os licitantes}

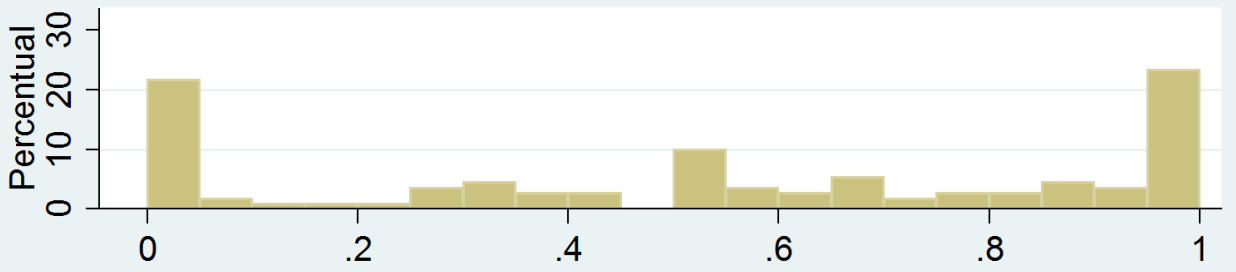

Licitações Abertas/ Licitações Totais

Licitantes com mais de 10 vitórias

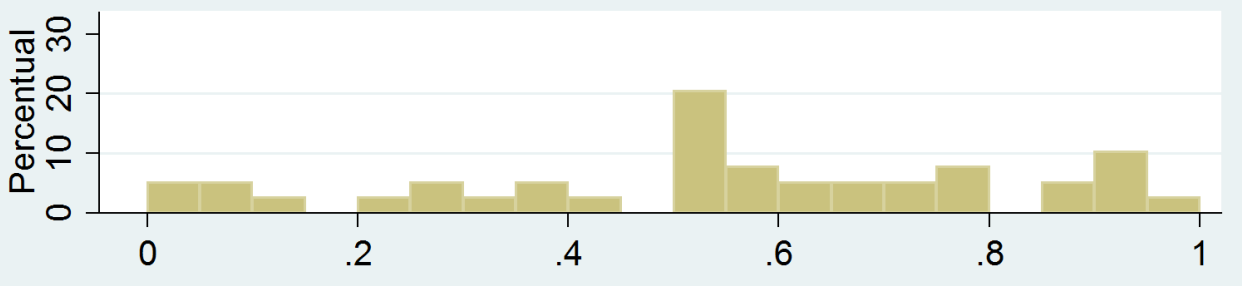

Licitações Abertas/ Licitações Totais

Fonte: BEC

Nota: Elaboração Própria 
Tabela 2 - Estatísticas descritivas das medidas de licitantes potenciais

\begin{tabular}{lccc}
\hline & $N_{1}$ & $N_{2}$ & $N_{3}$ \\
\hline Média & 1,38 & 3,64 & 13,57 \\
D. Padrão & 0,49 & 1,06 & 3,64 \\
Mínimo & 1 & 1 & 4 \\
Máximo & 2 & 6 & 23 \\
\hline
\end{tabular}

Fonte: BEC

Nota: Elaboração Própria. 


\section{Análise Empírica}

Este capítulo contém os principais resultados deste trabalho. Na seção 6.1 nós usamos regressões lineares para compararmos os formatos de licitações. Também utilizamos Propensity Score Matching para fazer uma comparação mais adequada entre os formatos e conseguir um teste de robustez do resultado anterior. Nos dois exercícios, a licitação selada gera um preço de compra menor que a licitação aberta.

Os exercícios descritos acima não nos permitem dizer as causas da diferença, pois ainda desconhecemos a função distribuição acumulada do custo de cada licitante e sua aversão ao risco. Por isso, na seção 6.2 estimamos a função distribuição de cada tipo de participante a partir dos nossos dados observados. Utilizamos o método de Brendstrup e Paarsch (2006) para estimar as funções usando somente os dados da licitação aberta. Para obter a função melhor resposta de cada licitante para a licitação selada, nós introduzimos nossa estimativa da função distribuição de cada licitante nas condições de primeira ordem da equação 4.7 e resolvemos o sistema de equações diferenciais de forma numérica com uma adaptação no método de Bajari (2001). Por fim, adotamos alguns valores para o parâmetro de aversão ao risco dos participantes e achamos evidência, através de nossas simulações, de que esta pode ser a razão para que haja diferença entre os formatos de licitação.

\subsection{Análise Exploratória}

Nesta seção, vamos comparar as duas modalidades de licitação em termos de preço usando regressões lineares e métodos de pareamento. As análises desta seção nos ajudam a entender o comportamento dos licitantes e nos auxiliam na estimação estrutural da seção 6.2 .

A regressão de interesse é:

$$
\ln P_{t}=\delta_{0}+\tau \cdot \text { selado }_{t}+X_{t}^{\prime} \delta+N_{t}^{p \prime} \lambda+\varepsilon_{t}, \quad t=1,2 \ldots T
$$

Onde $t$ é a licitação observada, $T$ é o total de licitações, $\ln P_{t}$ é o logaritmo natural 
do preço unitário do pacote de açúcar, $\tau$ é o coeficiente de interesse que indica o impacto do formato de licitação, selado $o_{t}$ é uma variável binária que indica 1 se a licitação for selada e 0 se licitação aberta. $X_{t}$ são controles de interesse e $N_{t}^{p}$ são variáveis que indicam o número de potenciais licitantes de cada tipo, enquanto $\delta$ e $\lambda$ são vetores de parâmetros e $\delta_{0}$ o intercepto da regressão. $\varepsilon_{t}$ é o termo aleatório da regressão.

Precisamos de $\mathbb{E}\left(\varepsilon \mid\right.$ selado $\left._{t}, X_{t}, N_{t}^{p}\right)=0$ para identificar os coeficientes. Diferentemente do trabalho de Athey, Levin e Seira (2011), a definição do formato de licitação na BEC não é aleatória. A unidade governamental (ou o funcionário público da entidade) determina a quantidade da compra e o formato da licitação. Contudo, há um interesse na unidade governamental em afetar o preço do produto? O burocrata que faz a requisição de compra do bem tem pouco incentivo (ou nenhum) para afetar o preço da transação. Sua remuneração não está condicionada às compras da unidade governamental nem há punições para o caso de preços altos. Assim, a decisão do processo de licitação está condicionada às facilidades do processo de criação do edital, hábitos anteriores da unidade pública, etc.

A quantidade pedida do bem, que pode gerar um valor que ultrapasse o limite da Dispensa de Licitação, está inclusa como controle. Ainda que os burocratas pudessem avisar para determinadas firmas que estão lançando um edital, esse movimento seria capturado pela medida de licitantes potenciais. Então, o formato da licitação não estaria correlacionado com o preço a não ser pela localização da unidade pública que implica gastos com fretes, seguros, etc. Como visto na seção anterior, a escolha do formato também não possui correlação com as medidas de licitantes potenciais, pois não há evidência que os licitantes arbitrem entre um formato ou outro. Assim, a condição de identificação dos coeficientes da regressão pode estar satisfeita.

A Tabela 3 mostra o resultado das regressões. As colunas de 1 a 3 mostram que a inserção das dummies de tempo e meses afetam pouco o resultado de 4,3\% a menos no preço da licitação selada em relação à licitação aberta. A introdução das dummies de cidade, indicada na coluna 4, mostra que a licitação selada gera um preço menor de aproximadamente $2,8 \%$, mostrando que a localização da unidade pública é algo relevante para determinar o preço de compra na licitação. 
Tabela 3 - Comparação de preço entre formatos de licitação

\begin{tabular}{ccccc}
\hline \multicolumn{5}{c}{$\ln$ (preço) } \\
\hline Variáveis & $(1)$ & $(2)$ & $(3)$ & $(4)$ \\
Independentes & & & & \\
selado & $-0,0433^{* * *}$ & $-0,0466^{* * *}$ & $-0,0465^{* * *}$ & $-0,0277^{* * *}$ \\
& $(0,0042)$ & $(0,0042)$ & $(0,0041)$ & $(0,0041)$ \\
$\ln$ (quantidade) & $-0,0252^{* * *}$ & $-0,0249^{* * *}$ & $-0,0258^{* * *}$ & $-0,0246^{* * *}$ \\
& $(0,0019)$ & $(0,0018)$ & $(0,0018)$ & $(0,0018)$ \\
$N_{1}$ & $-0,0080^{*}$ & $-0,0127^{* * *}$ & $-0,0316^{* * *}$ & $-0,0366^{* * *}$ \\
& $(0,0043)$ & $(0,0043)$ & $(0,0060)$ & $(0,0058)$ \\
$N_{2}$ & $-0,0152^{* * *}$ & $-0,0188^{* * *}$ & $-0,0104^{* * *}$ & $-0,0128^{* * *}$ \\
& $(0,0022)$ & $(0,0021)$ & $(0,0029)$ & $(0,0028)$ \\
$N_{3}$ & $-0,0007$ & $0,0015^{* *}$ & $-0,0000$ & $-0,0004$ \\
& $(0,0005)$ & $(0,0006)$ & $(0,0007)$ & $(0,0007)$ \\
dummies & Não & Sim & Sim & Sim \\
de ano & & & & \\
dummies & Não & Não & Sim & Sim \\
de mês & & & & Nim \\
dummies & Não & Não & Não & Sim \\
de município & & & 3.242 & 3.242 \\
Observações & 3.242 & 3.242 & 0,182 & 0,2905 \\
$\bar{R}^{2}$ & 0,107 & 0,1374 & & \\
\hline
\end{tabular}

Fonte: BEC

Notas: Elaboração Própria. Erros padrão robustos entre parêntesis. *** p-valor $<0,01,{ }^{* *}$ p-valor $<0,05,{ }^{*}$ p-valor $<0,1$

Mesmo que tenhamos $\mathbb{E}\left(\varepsilon \mid\right.$ selado, $\left.X, N^{p}\right)=0, \tau$ não pode ser interpretado como o efeito médio de ser alocado à licitação selada, ou em outras palavras, o efeito médio de tratamento da licitação selada, pois violamos a hipótese de overlap presente em Rosenbaum e Rubin (1983). Há cidades que somente possuem um formato de licitação (conforme Tabela 8 no Apêndice A), assim não temos $0<\operatorname{Pr}\left(\right.$ selado $\left.=1 \mid X, N^{p}\right)<1$ para toda licitação na nossa amostra. Para contornarmos esse problema, recorreremos à técnica de propensity score matching introduzida pelos mesmos autores. Trata-se de escolher, dentro da nossa amostra, as licitações abertas que são bastante próximas em termos de variáveis exógenas das licitações seladas e vice-versa. Como o pareamento exógena a exógena não é possível por causa do grande número de nossos controles, vamos fazer o pareamento via a probabilidade de cada licitação da nossa amostra ser aberta ou selada. 
A Tabela 4 mostra quais controles influenciaram o cálculo do propensity score, ou seja da probabilidade de uma licitação ser selada. Nota-se que a amostra utilizada para fazer esse logit é menor que o das regressões anteriores, pois não são contadas as licitações cujas cidades possuem apenas um formato de licitação. Nota-se também que a quantidade e as dummies de ano, mês e município contribuem para explicar a seleção do formato.

Tabela 4 - Propensity score sobre formato de

licitação

\begin{tabular}{lcc}
\hline Controles & Coeficiente & Erros Padrão \\
\hline $\ln$ (quantidade) & $0,1521^{* * *}$ & 0,0365 \\
$N_{1}$ & 0,0604 & 0,1274 \\
$N_{2}$ & 0,0304 & 0,0583 \\
$N_{3}$ & $-0,0159$ & 0,0164
\end{tabular}

Teste de Wald (p-valor em parêntesis)

dummies de tempo $\quad 65,21$

dummies de mês $\quad 21,83$

dummies de município $\quad 288,88$

$\begin{array}{lc}\text { Observações } & 3,062 \\ \text { log-verossimilhança } & -1824,14\end{array}$

Fonte: BEC

Notas: Elaboração Própria. Modelo Logit com dummy selado, como variável dependente. Testes de Wald foram feitos tomando todos os coeficientes iguas a zero como hipótese nula. ${ }^{* * *}$ p-valor $<0,01$, ${ }^{* *}$ p-valor $<0,05,{ }^{*}$-valor $<0,1$

Com a estimação acima, definimos o propensity score para cada licitação e escolhemos 3 observações do formato oposto que possuem o propensity score mais próximo do obtido para ela mesma. ${ }^{1}$ Lembrando que $\ln \left(P_{t}\right)$ é o logaritmo do preço para cada licitação, adote por $\widehat{\ln \left(P_{t}\right)}$ a média do logaritmo do preço obtido pelas observações pareadas. Vamos estimar a diferença entre as licitações, $\tau_{p s m}$, da seguinte forma:

$$
\tau_{p s m}=\frac{1}{T} \sum_{t \text { é selado }}\left(\ln \left(P_{t}\right)-\widehat{\ln \left(P_{t}\right)}\right)+\frac{1}{T} \sum_{t \text { é aberto }}\left(\widehat{\ln \left(P_{t}\right)}-\ln \left(P_{t}\right)\right)
$$

$\overline{1}$ Para os casos onde houve empate no propensity score, todas as observações do formato oposto foram utilizadas. 
A Tabela 5 mostra a estimativa por propensity score matching. O resultado encontrado de $3,89 \%$ é um pouco maior do que aquele obtido por regressões e sua significância estatística corrobora nossa evidência de que há alguma diferença entre as formas de licitação.

Após o matching, esperamos que a média ou proporção de cada controle seja similar em ambos formatos de licitação, caso contrário, nosso pareamento não teria sido feito adequadamente. Houve diferença de médias em somente dois dos 69 controles que utilizamos: nas dummies Mun $_{5}$ (Araraquara) e $M u n_{76}$ (Sertãozinho) com significância de 10\% e 5\%, respectivamente (informação presente na Tabela 9 do Apêndice A).

Estes dois procedimentos empíricos que fizemos mostram que o formato da licitação pode afetar, de fato, o preço do bem.

Tabela 5 - Efeito do formato de licitação

sobre $\ln ($ Preço $)$ por

Propensity Score Matching

\begin{tabular}{lcc}
\hline & Coeficiente & Erros Padrão \\
\hline$\tau_{p s m}$ & $-0,0388^{* * *}$ & 0,0050 \\
Observações & \multicolumn{2}{c}{3.062} \\
\hline
\end{tabular}

Fonte: BEC

Notas: Erros padrão robustos calculados segundo Abadie e Imbens (2009). ${ }^{* * *}$ p-valor $<0,01$ 


\subsection{Análise Estrutural}

A seção 6.1 nos permite verificar o tamanho da diferença do preço de compra entre as licitações, mas não nos permite verificar suas origens ou se o modelo do capítulo 4 é capaz de explicar as diferenças encontradas. Para encontrar as causas da diferença de preço entre os formatos, propomos estimar a função distribuição acumulada de custo de cada licitante, através dos dados do leilão aberto por máximo a verossimilhança. Nós colocamos nossa estimativa das funções de custo nas condições de primeira ordem do problema de maximização do participante na licitação selada e resolvemos o sistema de equações diferenciais numericamente. Assim, podemos obter a função melhor resposta de cada licitante e estamos aptos a verificar através de simulações, se nosso modelo é capaz de representar os padrões dos dados observados.

A simulação consiste em obter realizações aleatórias extraídas das funções de custo estimadas para cada licitante potencial em cada licitação da amostra. Em cada formato de licitação, é possível determinar o tipo e o lance do vencedor através da função melhor resposta de cada tipo de licitante. Por fim, também definimos alguns parâmetros de aversão ao risco de cada tipo de participante e achamos evidência de que este pode ser um fator importante para explicar a diferença entre os formatos de licitação.

A estimação da função custo utilizando somente os dados da licitação aberta se baseia numa variação paramétrica do estimador proposto por Brendstrup e Paarsch (2006) com uma adaptação para licitações. Deste artigo, sabemos que modelos de leilões abertos numa estrutura de IPV assimétrica são identificados quando se observa o número de participantes, suas identidades e o lance vencedor.

Como dito no capítulo 4 , o lance vencedor da licitação aberta é $B=C_{(N-1: N)}$, ou seja, igual ao segundo menor custo de $N$ potenciais participantes. Assim, o preço de transação que observamos nos nossos dados em uma licitação aberta é igual ao segundo menor custo sorteado entre os licitantes. Como estamos com um modelo assimétrico, não podemos obter a distribuição de custo de cada tipo de participante somente com a densidade de $B=C_{(N-1: N)}$. 
Para a estimação da função custo de cada tipo, estamos interessados no evento: Qual a probabilidade de um licitante $i$ vencer uma licitação possuindo um custo maior ou igual a $c$ ? Este evento, é descrito como a função sobrevivência $G_{(N-1: N)}(c, i)$. Como conhecemos a identidade do vencedor e podemos estimar a densidade do segundo menor custo, também podemos estimar $G_{(N-1: N)}(c, i)$. Note que por ser uma função sobrevivência, ela deve tender a zero conforme o custo $c$ se aproxime do custo máximo $\bar{c}$, pois as chances de vitória se tornariam nulas com um custo muito alto. A seguir, adotaremos também a notação $F_{\text {tipo(i) }}$ que indica o tipo da função distribuição acumulada do licitante $i$. Por exemplo, se o indivíduo $i$ for do tipo Médio, $F_{\text {tipo }(i)}$ será igual a $F_{2}$.

$G_{(N-1: N)}(c, i)$ é composta pela soma de dois eventos disjuntos:

i) $i$ possui custo menor que $c$ e demais licitantes possuem custo maior que $c$;

ii) demais licitantes possuem custo maior que $i$, e $i$ possui custo maior ou igual a $c$.

De modo formal temos:

$$
\begin{aligned}
G_{(N-1: N)}(c, i) & =\operatorname{Pr}(i \text { vencer com lance } B \geq c) \\
& =\operatorname{Pr}\left(c_{i} \leq c, c_{j} \geq c, \forall j \neq i\right)+\operatorname{Pr}\left(c_{i} \leq c_{j}, c_{i} \geq c, \forall j \neq i\right) \\
& =F_{\text {tipo }(i)}(c) \prod_{j \neq i}\left(1-F_{\text {tipo }(j)}(c)\right)+ \\
& +\int_{c}^{\bar{c}} \prod_{j \neq i}\left(1-F_{\text {tipo }(j)}(y)\right) d F_{\text {tipo }(i)}(y)
\end{aligned}
$$

Derivando a equação 6.3 em relação a $c$ de ambos os lados temos:

$$
\begin{aligned}
\frac{d G_{(N-1: N)}(c, i)}{d c} & =F_{\text {tipo }(i)}(c) d \prod_{j \neq i}\left(1-F_{\text {tipo }(j)}(c)\right)+\frac{f_{\text {tipo }(i)}(c) \prod_{j \neq i}\left(1-F_{t i p o(j)}(c)\right)}{} \\
& -\prod_{j \neq i}\left(1-F_{\text {tipo }(j)}(c)\right) f_{\text {tipo }(i)}(c) \\
g_{(N-1: N)}(c, i) & =F_{\text {tipo }(i)}(c) d \prod_{j \neq i}\left(1-F_{\text {tipo }(j)}(c)\right) \\
& =-F_{\text {tipo }(i)}(c)\left(\sum_{j \neq i} f_{\text {tipo }(j)}(c) \prod_{k \neq j, i}\left(1-F_{\text {tipo }(k)}(c)\right)\right)
\end{aligned}
$$

A função $g_{(N-1: N)}(c, i)$ é a derivada com relação a $c$ da função sobrevivência $G_{(N-1: N)}(c, i)$. Como se pode ver pela equação 6.4 , ela é negativa, pois é a derivada de uma função sobrevivência, ou de outra forma, o negativo de uma função densidade de 
probabilidade. Defina $g_{(N-1: N)}^{*}(c, i) \equiv-g_{(N-1: N)}(c, i)$ e adote também que $n_{1}, n_{2}$ e $n_{3}$ indicam, respectivamente, o número de oponentes do tipo 1, 2 e 3 enfrentados pelo licitante $i$. Vamos escrever essa função densidade em termos dos três tipos de licitantes do nosso modelo:

$$
\begin{aligned}
g_{(N-1: N)}^{*}(c, i) & =F_{t i p o(i)}(c) \cdot\left\{n_{1} f_{1}(c)\left[1-F_{1}(c)\right]^{n_{1}-1}\left[1-F_{2}(c)\right]^{n_{2}}\left[1-F_{3}(c)\right]^{n_{3}}\right. \\
& +n_{2} f_{2}(c)\left[1-F_{1}(c)\right]^{n_{1}}\left[1-F_{2}(c)\right]^{n_{2}-1}\left[1-F_{3}(c)\right]^{n_{3}} \\
& \left.+n_{3} f_{3}(c)\left[1-F_{1}(c)\right]^{n_{1}}\left[1-F_{2}(c)\right]^{n_{2}}\left[1-F_{3}(c)\right]^{n_{3}-1}\right\}
\end{aligned}
$$

Vamos usar a equação 6.5 para criarmos um estimador de máximo a verossimilhança. Para isso, vamos adotar que as funções custo possuem a distribuição de uma Weibull, com seguinte formato:

$$
F_{m}\left(c \mid X_{\alpha}, X_{\beta} ; \boldsymbol{\alpha}_{m}, \boldsymbol{\beta}_{m}\right)=1-\exp \left(\frac{c}{\alpha_{m}\left(X_{\alpha}\right)}\right)^{\beta_{m}\left(X_{\beta}\right)}, \quad m=1,2 \text { e } 3
$$

Onde $\alpha_{m}\left(X_{\alpha}\right)$ e $\beta_{m}\left(X_{\beta}\right)$ são dados por:

$$
\begin{aligned}
& \alpha_{m}\left(X_{\alpha}\right)=\alpha_{0}^{m}+X_{\alpha} \alpha_{X}^{m}, \quad m=1,2 \text { е } 3 \\
& \beta_{m}\left(X_{\beta}\right)=\beta_{0}^{m}+X_{\beta} \beta_{X}^{m}, \quad m=1,2 \text { е } 3
\end{aligned}
$$

Os termos $\alpha_{m}\left(X_{\alpha}\right)$ e $\beta_{m}\left(X_{\beta}\right)$ são respectivamente os coeficientes de escala e forma da distribuição Weibull de cada tipo de licitante. $X_{\alpha}$ e $X_{\beta}$ são os controles utilizados para os coeficientes de escala e forma, respectivamente. Para os coeficientes de forma de cada tipo, utilizamos como controles as variáveis binárias de mês. Para os coeficientes de escala utilizamos a quantidade vendida na licitação, as dummies de ano e uma agregação das variáveis binárias de cada município em 5 regiões: Centro, Norte, Sul, Litoral e Grande São Paulo. A agregação está descrita na Tabela 10 no Apêndice A e seguiu a proximidade das Regiões Administrativas do Estado. ${ }^{2}$

$\overline{2}$ A agregação se fez necessária por dois motivos. Primeiramente, não foi possível satisfazer a condição de segunda ordem do problema de máximo a verossimilhança devido à baixa quantidade de licitações 
Os termos $\alpha_{X}^{m}$ e $\beta_{X}^{m}$ são vetores de parâmetros, enquanto $\alpha_{0}^{m}$ e $\beta_{0}^{m}$ indicam os valores dos parâmetros de escala e forma quando os controles respectivos são iguais a 0 , por fim, $\boldsymbol{\alpha}_{m}$ e $\boldsymbol{\beta}_{m}$ representam todos os parâmetros utilizados para cada coeficiente e tipo de licitante, enquanto $\boldsymbol{\alpha}$ e $\boldsymbol{\beta}$ representam todos os parâmetros (independentemente do tipo de licitante) para os coeficientes de escala e forma, respectivamente.

Indexando por $t$ as observações e usando a equação 6.5 podemos introduzir a função de log-verossimilhança:

$$
\begin{aligned}
\ln \mathcal{L}(\boldsymbol{\alpha}, \boldsymbol{\beta}) & =\sum_{t=1}^{T} \ln g_{(N-1: N)}^{*}\left(c_{t}, i_{t} ; \boldsymbol{\alpha}, \boldsymbol{\beta}\right) \\
\ln \mathcal{L}(\boldsymbol{\alpha}, \boldsymbol{\beta}) & =\sum_{t=1}^{T} \ln F_{t i p o(i)}\left(c_{t} \mid X_{\alpha}, X_{\beta} ; \boldsymbol{\alpha}_{t i p o(i)}, \boldsymbol{\beta}_{\text {tipo }(i)}\right) \\
& +\sum_{t=1}^{T} \ln \left\{n_{1 t} f_{1}\left(c_{t} \mid X_{\alpha}, X_{\beta} ; \boldsymbol{\alpha}_{1}, \boldsymbol{\beta}_{1}\right)\left[1-F_{1}\left(c_{t} \mid X_{\alpha}, X_{\beta} ; \boldsymbol{\alpha}_{1}, \boldsymbol{\beta}_{1}\right)\right]^{n_{1 t}-1}\right. \\
& \cdot\left[1-F_{2}\left(c_{t} \mid X_{\alpha}, X_{\beta} ; \boldsymbol{\alpha}_{2}, \boldsymbol{\beta}_{2}\right)\right]^{n_{2 t}}\left[1-F_{3}\left(c_{t} \mid X_{\alpha}, X_{\beta} ; \boldsymbol{\alpha}_{3}, \boldsymbol{\beta}_{3}\right)\right]^{n_{3 t}} \\
& +n_{2 t} f_{2}\left(c_{t} \mid X_{\alpha}, X_{\beta} ; \boldsymbol{\alpha}_{2}, \boldsymbol{\beta}_{2}\right)\left[1-F_{1}\left(c_{t} \mid X_{\alpha}, X_{\beta} ; \boldsymbol{\alpha}_{1}, \boldsymbol{\beta}_{1}\right)\right]^{n_{1 t}} \\
& \cdot\left[1-F_{2}\left(c_{t} \mid X_{\alpha}, X_{\beta} ; \boldsymbol{\alpha}_{2}, \boldsymbol{\beta}_{2}\right)\right]^{n_{2 t}-1}\left[1-F_{3}\left(c_{t} \mid X_{\alpha}, X_{\beta} ; \boldsymbol{\alpha}_{3}, \boldsymbol{\beta}_{3}\right)\right]^{n_{3 t}} \\
& +n_{3 t} f_{3}\left(c_{t} \mid X_{\alpha}, X_{\beta} ; \boldsymbol{\alpha}_{3}, \boldsymbol{\beta}_{3}\right)\left[1-F_{1}\left(c_{t} \mid X_{\alpha}, X_{\beta} ; \boldsymbol{\alpha}_{1}, \boldsymbol{\beta}_{1}\right)\right]^{n_{1 t}} \\
& \left.\cdot\left[1-F_{2}\left(c_{t} \mid X_{\alpha}, X_{\beta} ; \boldsymbol{\alpha}_{2}, \boldsymbol{\beta}_{2}\right)\right]^{n_{2 t}}\left[1-F_{3}\left(c_{t} \mid X_{\alpha}, X_{\beta} ; \boldsymbol{\alpha}_{3}, \boldsymbol{\beta}_{3}\right)\right]^{n_{3 t}-1}\right\}
\end{aligned}
$$

Os parâmetros estimados pela equação 6.9 são mostrados na Tabela 6. Essa estimação das funções custo possui algumas vantagens. Ela comporta um grande número de controles e os três tipos de licitantes do nosso modelo. Técnicas não paramétricas são muito mais intensivas em dados e não se adequariam aos nossos dados observados. Como não observamos todos os lances dos licitantes, nós não podemos usar as técnicas presentes em Campo et al. (2011), Campo (2012) ou mesmo a de Athey, Levin e Seira (2011) assumindo neutralidade ao risco. Uma outra alternativa seria o método proposto por Athey e Haile (2007, eq. 3.8). Os autores propõem recuperar a distribuição de todos os lances da licitação selada através das densidades dos lances vencedores de cada tipo e depois aplicar o método de Guerre, Perrigne e Vuong (2000) para recuperar a função

em alguns municípios. Outro motivo se deve a alguns municípios terem realizado somente um tipo de licitação, o que nos impossibilitaria de realizar a simulação para a licitação selada que faremos a seguir. 


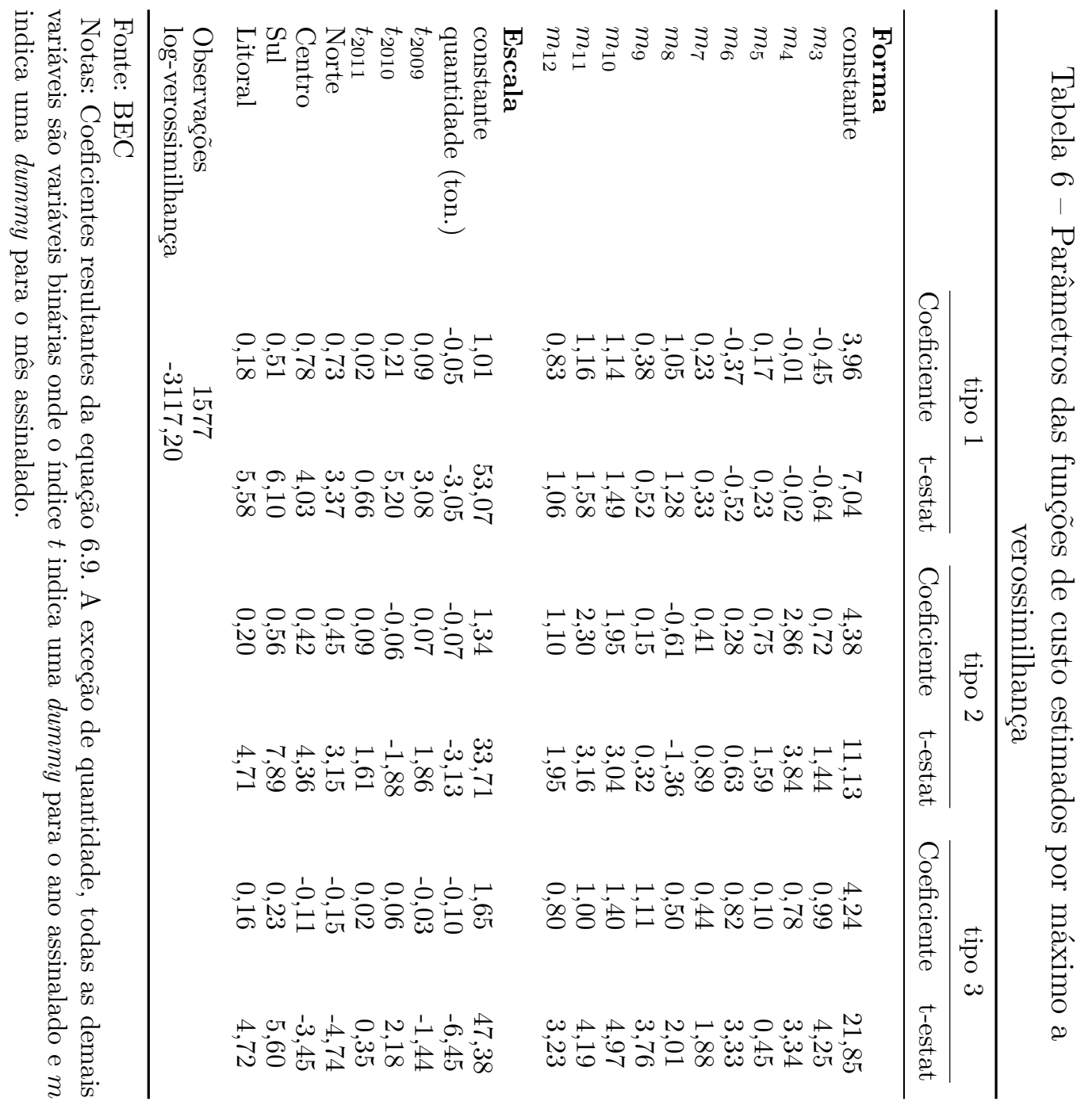


Figura 7 - Função distribuição acumulada estimada para cada tipo de licitante

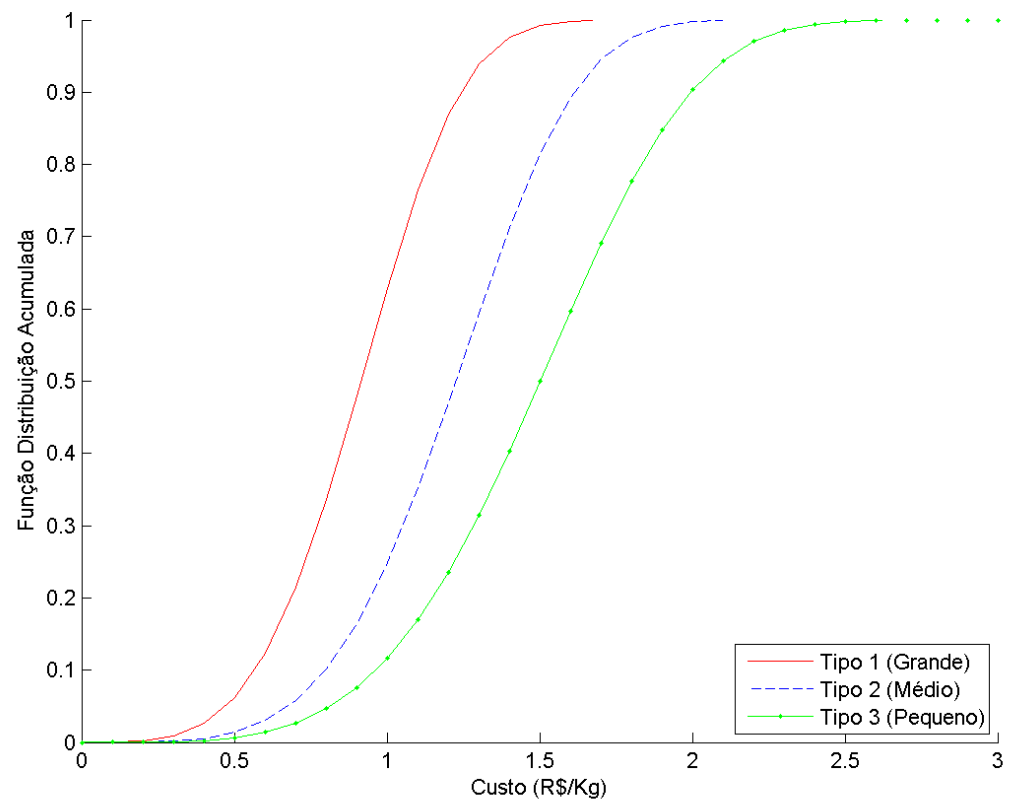

Fonte: BEC.

Notas: Elaboração Própria. A figura mostra a função distribuição acumulada dos 3 tipos de licitantes para o mês de fevereiro de 2008, na Grande São Paulo e com quantidade demandada de 100 unidades.

custo de forma indireta sob neutralidade ao risco. Com essa proposta, teríamos que aplicar um método não paramétrico com poucas observações e muitos controles para recuperar a distribuição de custo, o que poderia levar a uma grande imprecisão.

A Figura 7 e a Figura 8 mostram a função distribuição e a função densidade de cada tipo de licitante, respectivamente. Como era de se esperar, a função distribuição do tipo grande está à esquerda das demais, implicando que o tipo 1 tende a ter custos sorteados menores que os demais. O mesmo se aplica para o tipo 2 em relação ao tipo 3. Nós não impomos essa restrição na estimação e é possível que para algumas licitações da nossa amostra esse padrão não se repita, ou que alguma função distribuição se cruze com outra em algum ponto.

A simples obtenção das funções de custo não é suficiente para fazermos as simulações necessárias para descobrir a origem da diferença entre os preços das duas formas de licitação. Precisamos obter também a estratégia ótima para cada tipo de participante na licitação selada. Para obter essa estratégia ótima dos tipos, vamos usar o terceiro algoritmo de Bajari (2001) com uma modificação inspirada em Hubbard e Paarsch (2014). 
Figura 8 - Função densidade estimada para cada tipo de licitante

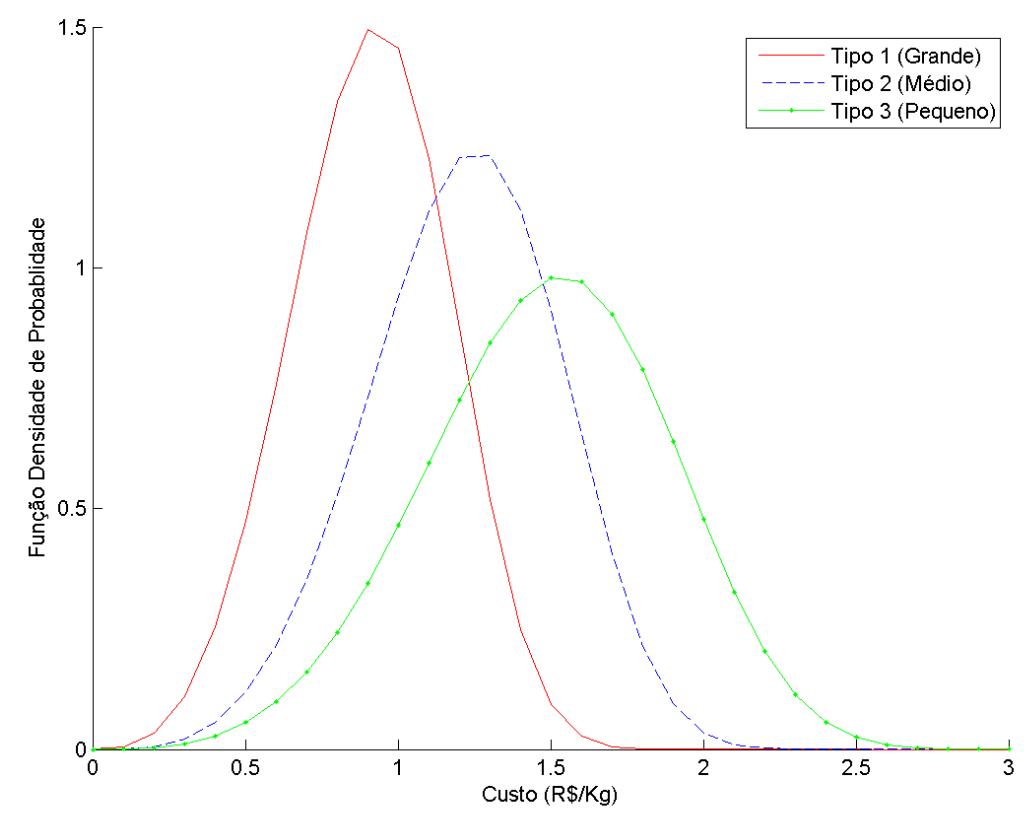

Fonte: BEC.

Nota: Elaboração Própria. A figura mostra a função densidade de probabilidade dos 3 tipos de licitantes para o mês de fevereiro de 2008, na Grande São Paulo e com quantidade demandada de 100 unidades.

Vamos introduzir a estimativa da função custo nas condições de primeira ordem de um licitante no formato selado (mostrada na equação 4.7) e resolver o sistema de equações diferenciais de forma numérica junto com as condições de contorno do mesmo problema (representada pelas equações 4.8 e 4.9). O algoritmo consiste em aproximar a função inversa da estratégia ótima, $\phi_{m}(b)$, por um polinômio de ordem escolhida que melhor resolva o sistema de equações diferenciais. De maneira formal, temos:

$$
\phi_{m}(b ; \underline{b}, \theta)=\underline{b}+\sum_{k=0}^{K} \theta_{k}^{m}(b-\underline{b})^{k}
$$

Vamos reescrever o sistema 4.7 em forma de índices e somatórios e aplicar a nossa estimativa $\hat{F_{m}}(c)$ da função custo:

$$
1=\gamma_{m}\left(b-\phi_{m}(b)\right) \sum_{l=1}^{3} n_{l} \frac{\hat{f}_{l}\left(\phi_{l}(b)\right)}{1-\hat{F}_{l}\left(\phi_{l}(b)\right)} \phi_{l}^{\prime}(b), \quad m=1,2 \text { e } 3
$$

Denote por $\boldsymbol{\theta}$ o vetor que inclui todos coeficientes dos polinômios da equação 6.10 e defina $G_{m}(b, \underline{b}, \boldsymbol{\theta})$ como:

$$
G_{m}(b, \underline{b}, \boldsymbol{\theta}) \equiv 1-\gamma_{m}\left(b-\phi_{m}(b)\right) \sum_{l=1}^{3} n_{l} \frac{\hat{f}_{l}\left(\phi_{l}(b)\right)}{1-\hat{F}_{l}\left(\phi_{l}(b)\right)} \phi_{l}^{\prime}(b), \quad m=1,2 \text { e } 3
$$


Avaliaremos a equação 6.12 em $P$ pontos uniformemente distribuídos dentro do intervalo $[\underline{b}, \bar{c}]$, onde acrescentaremos as condições iniciais 4.8 e 4.9 para formar o seguinte funcional:

$$
\tilde{H}(\underline{b}, \boldsymbol{\theta}) \equiv \sum_{m=1}^{3} \sum_{p=1}^{P}\left[G_{m}\left(b_{p}, \underline{b}, \boldsymbol{\theta}\right)\right]^{2}+P \sum_{m=1}^{3}\left[\bar{c}-\phi_{m}(\bar{c})\right]^{2}+P \sum_{m=1}^{3}\left[\underline{c}-\phi_{m}(\underline{b})\right]^{2}
$$

Quando a equação 6.13 for igual a zero, tanto o sistema 4.3 e suas condições iniciais serão satisfeitas. ${ }^{3}$ Neste trabalho, estabelecemos a ordem do polinômio como $K=5$ e o número de pontos como $P=500$. Como encontraremos a solução para polinômios de ordem finita, descobriremos os polinômios e o lance mínimo $\underline{b}$ que minimizam a equação 6.13 .

Inspirando-se em Hubbard e Paarsch (2014, seção 4.7) nós imporemos restrições na minimização usando teoria econômica. A primeira delas é impor monotonicidade na solução. A segunda consiste em $b-\phi_{m}(b) \geq 0$ que diz que os participantes não darão um lance abaixo do seu custo. Também acrescentamos $\underline{c} \leq \phi_{m} \leq \bar{c}$, pois a equação 6.13 não necessariamente garante esse resultado. ${ }^{4}$ Assim, o problema a ser resolvido é:

$$
\begin{array}{ll}
\min _{\underline{b}, \boldsymbol{\theta}} & \tilde{H}(\underline{b}, \boldsymbol{\theta}) \\
\text { s.a } & \phi_{m}\left(b_{p-1}\right) \leq \phi_{m}\left(b_{p}\right) \text { para um intervalo uniforme de pontos } p=2 \ldots P \\
& \phi_{m}^{\prime}\left(b_{p}\right) \geq 0 \text { para } p=1 \\
& b_{p}-\phi_{m}\left(b_{p}\right) \geq 0 \\
& \underline{c} \leq \phi_{m}\left(b_{p}\right) \leq \bar{c}
\end{array}
$$

Resolveremos o problema 6.14 para cada licitação $t$ da nossa amostra, pois cada uma delas possui número de licitantes potenciais diferentes e controles diferentes. O suporte da distribuição de custo estimada é $[0, \infty)$ o que nos leva a truncá-la para avaliarmos a

3 A equação 6.13 difere em 2 aspectos da equação 16 de Bajari (2001). A primeira diferença deve-se à inexistência do termo $\gamma_{m}$ (ou $\gamma_{m}=1$ ) pois o autor assume agentes neutros ao risco em seu trabalho. A segunda diferença surge da ausência de pesos nas condições iniciais no texto do autor, contudo Hubbard e Paarsch (2014, p. 83) mencionam que o autor usou uma versão com pesos em seu trabalho.

4 Essas restrições também possuem razões computacionais. Como resolveremos o problema 6.14 para cada observação da amostra, não é possível checar se elas satisfazem todas as condições citadas. Além disso, essas restrições diminuem o tempo de minimização. 
Figura 9 - Função melhor resposta de cada tipo de licitante

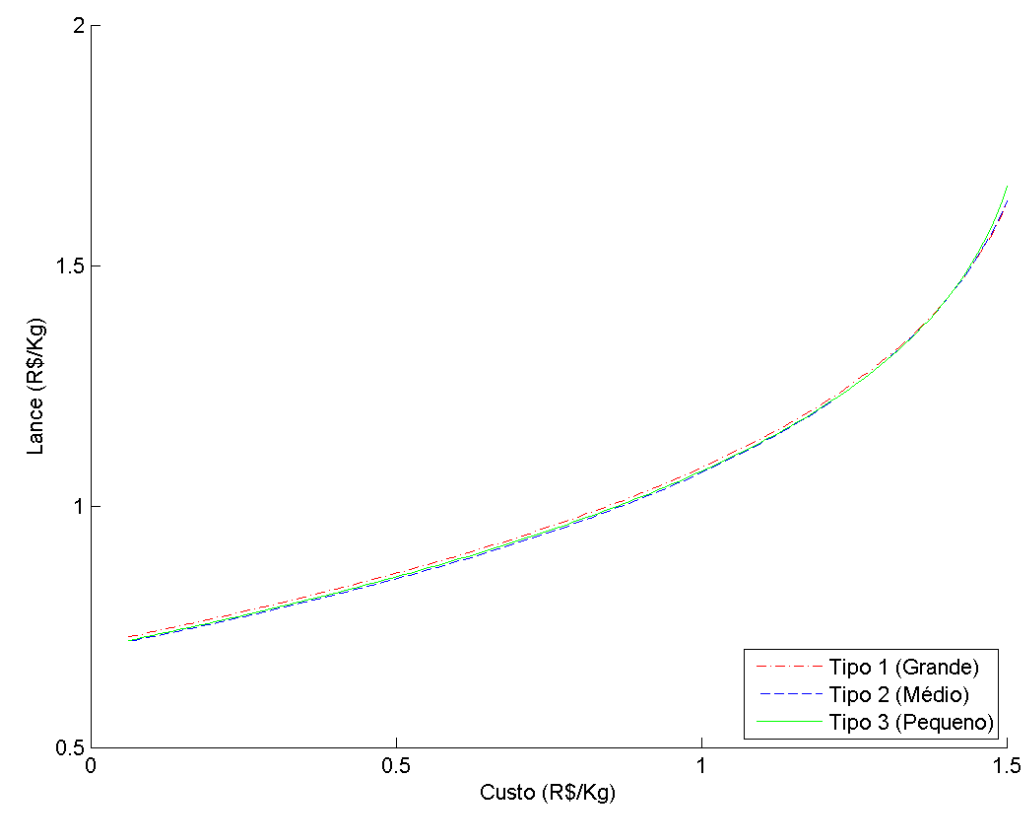

Fonte: BEC.

Nota: Elaboração Própria. A figura mostra o lance dos 3 tipos de licitantes em função do custo $c$ sorteado para o mês de fevereiro de 2008, na Grande São Paulo, com quantidade demandada de 100 unidades e $N_{1}=1, N_{2}=3$ e $N_{3}=11 . \underline{b}=0.7251$ foi o lance mínimo encontrado na resolução da equação 6.14 .

função em um intervalo de pontos finito. ${ }^{5}$

A Figura 9 mostra a melhor resposta de cada tipo de licitante em relação ao custo $c$ e seus competidores. As curvas são muito próximas diferindo apenas em centavos. Também se nota que as curvas não satisfazem perfeitamente as condições de contorno resultantes das condições de primeira ordem.

A simulação consiste em obter realizações aleatórias extraídas das funções custo estimadas para cada licitante potencial em cada licitação da amostra. Para o leilão aberto, declaramos como vencedor aquele que obteve o menor custo e adotamos como lance vencedor o segundo menor custo. Para a licitação selada, introduzimos o custo sorteado dentro da função obtida pela solução do problema 6.14, assim é possível obter o lance correspondente a cada licitante e determinar o vencedor. ${ }^{6}$ Da mesma forma que em Athey,

5 Nós truncamos a função distribuição no ponto $c_{u p p e r}^{m}$ em que $\hat{F_{m}}\left(c_{u p p e r}^{m}\right)=0.999999$. Contudo, $c_{u p p e r}$ deve ser o mesmo para todos os tipos, segundo o modelo. Então, para cada observação $t$ adotamos $\bar{c}=\max \left\{c_{\text {upper }}^{1}, c_{\text {upper }}^{2}, c_{\text {upper }}^{3}\right\}$. Também truncamos a cauda inferior nas simulações no ponto $c_{\text {lower }}^{m}$ em que $\hat{F_{m}}\left(c_{\text {lower }}^{m}\right)=0.000001$ e fizemos $\underline{c}=\min \left\{c_{\text {lower }}^{1}, c_{\text {lower }}^{2}, c_{\text {lower }}^{3}\right\}$

6 Para encontrarmos o lance de cada licitante, nós calculamos as raízes do polinômio $\widetilde{\phi_{m}}(b)=\phi_{m}(b)-c_{s}$, 
Levin e Seira (2011), nossas previsões para a licitação selada são fora da amostra (out-ofsample) em dois sentidos. O primeiro deles consiste em que a previsão é feita para uma amostra cujas observações não foram usadas na estimação. O segundo deles reside em que o formato da licitação também não é o mesmo da amostra usada na estimação.

A Tabela 7 mostra os resultados da simulação para várias medidas de interesse. Para o formato aberto constatamos que o modelo faz uma aproximação muito boa. O valor simulado para a média do lance vencedor e o custo total médio são bastante próximos dos observados nos dados. As proporções de vitórias simuladas do tipo 2 e 3 estão bem próximas dos valores reais considerando o intervalo de confiança de $95 \%$, enquanto que a proporção de vitórias do tipo 1 está bem próxima do valor observado de $31 \%$ se adotarmos um intervalo de confiança de $99 \%$. Com relação à média dos lances vencedores de cada tipo, nota-se que nosso modelo tende a superestimar os lances vencedores do tipo 1 e subestimar os lances vencedores do tipo 3. Contudo não se pode rejeitar que os valores simulados são diferentes dos observados com nível de significância de $10 \%$.

A simulação para a licitação selada com neutralidade ao risco mostra uma conclusão contrária aos resultados da seção 6.1, onde a licitação selada obteve um preço menor que a aberta. Apesar do preço unitário de $\mathrm{R} \$$ 0,9271 da licitação selada ser inferior ao preço observado de $\mathrm{R} \$ 0,9334$ da licitação aberta, o valor de $\mathrm{R} \$ 0,9334$ ainda se encontra no intervalo de confiança da licitação selada. Desta forma, não podemos dizer que há diferença entre os formatos de licitação. Na simulação, apesar do custo total médio simulado estar próximo do valor observado, a licitação selada gera um custo unitário de $\mathrm{R} \$ 0,04$ (4,8\%) a mais que o observado. Isso nos indica que alguma hipótese do nosso modelo foi violada ou que desconsideramos fatores importantes no modelo ou na estimação.

Os resultados da simulação seriam inválidos se nos nossos dados houvesse algum

onde $\phi_{m}(b)$ é a solução de 6.14 e $c_{s}$ é o custo sorteado. Na obtenção dessas raízes podem surgir alguns problemas, pois $\phi_{m}(b)$ não é necessariamente monotônico em todo intervalo $[\underline{c}, \bar{c}]$, pois as condições de contorno não precisam ser satisfeitas exatamente. Em concreto, é possível obter mais de uma raiz real ou nenhuma raíz real para algumas realizações. No primeiro caso, escolhemos a menor. No segundo caso adotamos que o licitante dá um lance igual a seu custo. Acreditamos que esse não é um problema grave, pois os $\phi_{m}(b)$ de cada observação são monotônicos do início do suporte e deixam de sê-lo em algum ponto no interior do suporte, o que não traz nenhum problema para aqueles licitantes com as menores realizações e que de fato ganhariam a licitação. Como há no mínimo dez licitantes para cada observação da amostra, é difícil que esse problema ocorra para todos os sorteios. 


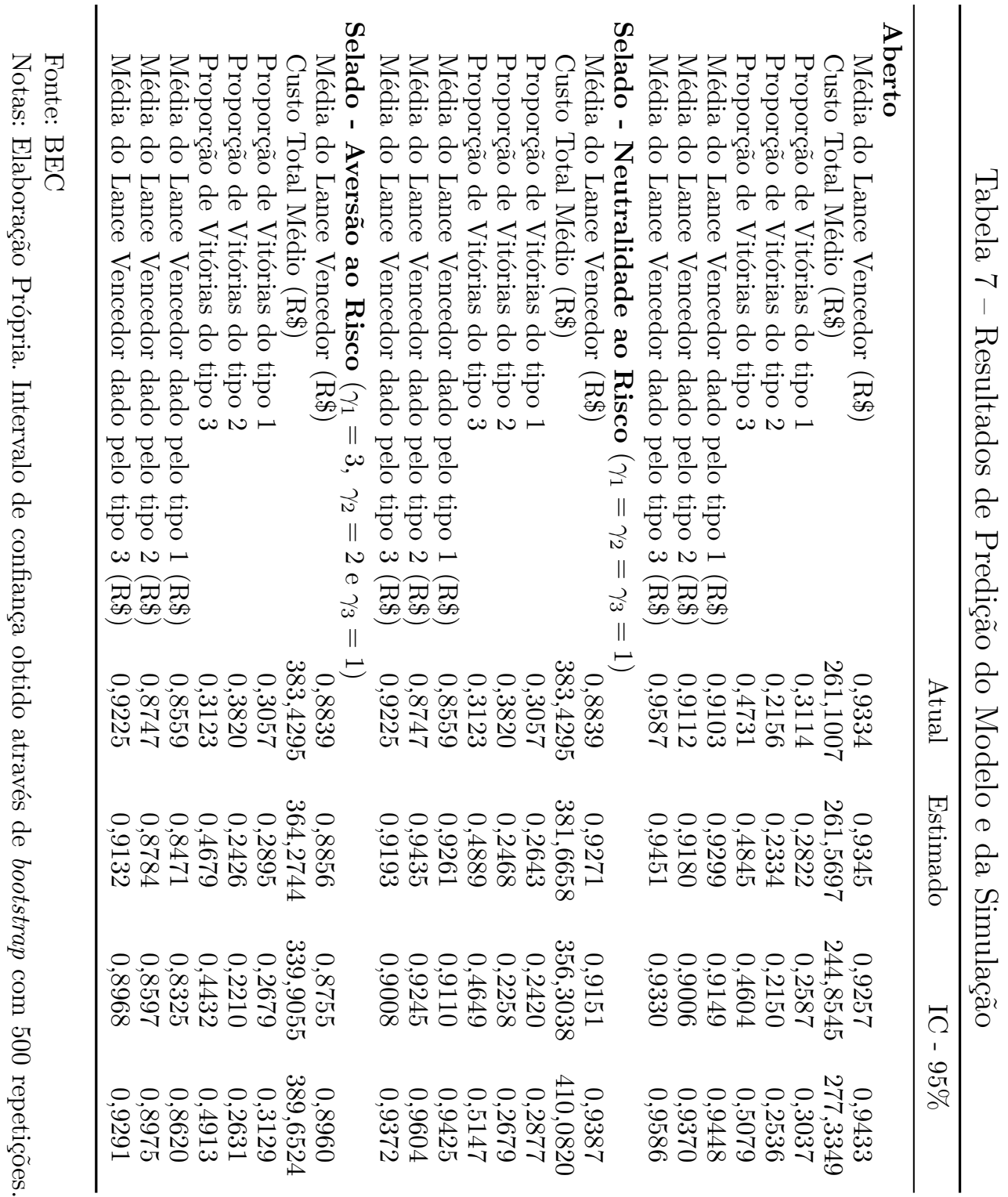


tipo de correlação entre os custos dos licitantes, pois invalidaria nossa hipótese de independência. Tal correlação poderia vir de alguma interdependência entre as funções custo, alguma heterogeneidade não observável, conluio entre os participantes ou alguma forma de corrupção.

A interdependência não capturada pelas funções custo teria que ser acomodada por um modelo que assumisse licitantes capazes de aprender seu próprio custo com os sinais enviados de outros licitantes. ${ }^{7}$ Como o bem tratado nesse trabalho é bastante simples, nos parece bastante possível que os licitantes saibam exatamente quanto este bem de fato lhes custou. A hipótese de interdependência se aplicaria melhor a serviços ou concessões de obras públicas que envolvem muitos insumos e inúmeras formas de realizar o contrato com o governo.

Se há alguma característica na licitação observada por todos os participantes e não pelo pesquisador, temos o problema de heterogeneidade não observável cujos erros ao ser desconsiderada são descritos em Krasnokutskaya (2011). Na nossa amostra, todas as informações relevantes estão descritas no edital, por isso, acreditamos que este não é o motivo da diferença encontrada entre as simulações e as regressões.

Conluio é sempre possível em qualquer tipo de licitação ou leilão. Athey, Levin e Seira (2011) estimam a função distribuição dos tipos assumindo comportamento competitivo no leilão selado e assumem em seu modelo conluio completo entre os grandes competidores no leilão aberto. Contudo os dados não favorecem conluio completo, mas em uma frequência de $18 \%$ das vezes. Por estudarmos uma licitação eletrônica, a comunicação entre os licitantes durante o processo de compra é perfeitamente possível em qualquer formato de licitação. Todavia, a comunicação é dificultada pelo desconhecimento das identidades dos licitantes durante a competição numa dada licitação. O valor baixo dos bens estudados neste trabalho também não corrobora para a presença de conluio, porém poderia ocorrer em modalidades de valores mais altos como o Pregão realizado na BEC.

Uma possível forma de corrupção neste sistema eletrônico que passaria despercebido aos demais licitantes seria o vazamento dos lances de concorrentes durante a licitação

$\overline{7} \quad$ Isto corresponde ao modelo de Affiliated Private Values descrito em Milgrom e Weber (1982). 
selada. Contudo, essa possibilidade é pouco plausível, pois geraria um custo maior por conta do Estado, resultado oposto ao que encontramos na seção 6.1.

Se, de fato, tivermos uma estrutura competitiva para a licitação aberta, a diferença poderia ser explicada por aversão ao risco. Por isso, na Tabela 7 propomos um análise exploratória em termos dos parâmetros de aversão ao risco como tentativa de explicação para o fenômeno. Estabelecemos $\gamma_{1}=3, \gamma_{2}=2$ e $\gamma_{3}=1$. Nota-se que o preço unitário decai com a presença de aversão ao risco o que pode ser uma explicação para o nosso resultado. Com esses valores, todos as medidas simuladas se encontram próximas dos valores observados em termos do intervalo de confiança, com exceção das proporções de vitórias do tipo 2 e 3 . É possível que a forma como definimos os licitantes potenciais interfira nessas proporções, pois a diferença entre os tipos Médio e Pequeno não é facilmente distinguível pela frequência de vitórias. Essa diferença pode implicar também que um modelo com dois tipos seria adequado para chegarmos ao mesmo resultado em termos de preço.

Os parâmetros estabelecidos também possuem interpretação econômica. O tipo Grande possui uma aversão ao risco maior que os demais, pois grande parte da sua receita habitual procederia de suas vendas na BEC. Assim, derrotas na licitação selada implicariam em grandes perdas para seu faturamento. O tipo Pequeno é neutro ao risco, pois possuiria muitas outras formas de receita fora da BEC e a usa como forma de obter receitas extras. O tipo Médio seria o meio termo entre os dois anteriores.

É importante ressaltar que esses valores de aversão ao risco não foram estimados dos dados. A estimação de modelos com aversão ao risco se apoia em hipóteses adicionais de identificação e da observação de todos os lances. ${ }^{8}$ A estimativa desses parâmetros é uma agenda de pesquisa futura, pois pode-se utilizar os dois formatos de licitação para gerar mais condições de identificação de modo análogo a Lu e Perrigne (2008).

Uma possível interpretação do nosso parâmetro de aversão ao risco é a de que os licitantes se comportam como se houvesse mais licitantes do que os que de fato

$8 \quad$ Veja Campo et al. (2011) para mais detalhes. 
existem. ${ }^{9}$ Isso é particularmente importante numa licitação online onde os licitantes não sabem exatamente quantos competidores enfrentam. Este efeito é menos aparente na licitação aberta, pois o licitante sabe que está vencendo ou perdendo. Desta forma, não necessariamente podemos explicar a diferença entre os formatos por aversão ao risco, mas também por alguma expectativa de mais licitantes potenciais do que a competição real.

Assim, apesar de não ser possível separar estes dois efeitos, o uso da licitação selada geraria preços mais favoráveis ao Estado, o que nos permite fazer uma recomendação de política pública quanto à forma das licitações de materiais e em particular no bem que analisamos. No Apêndice A, a Tabela 11 e a Tabela 12 mostram os resultados das regressões e das simulações com outros critérios de classificação dos licitantes. Estas tabelas mostram que os resultados desse trabalho permanecem se introduzirmos uma mudança marginal no critério de classificação dos licitantes. Assim, acrescentamos alguma robustez aos resultados desse trabalho.

Por fim, ainda que ocorra competição na licitação aberta, há um fator que não é incorporado ao clock model que usamos. Devido ao desconhecimento do lance vencedor dentro do processo da licitação aberta, é possível que ocorram jump bids, ou seja, lances bem menores que o segundo menor custo, invalidando assim a equação 6.9. Isto implicaria que o preço de transação observado não seria igual ao segundo menor custo. Haile e Tamer (2003) estimam limites para a distribuição de custo na presença de jump bids e outras condições não contempladas pelo clock model sob simetria. Não é possível estimarmos estes limites, pois não observamos todos os lances dos participantes e assumimos assimetria. A aproximação numérica que usamos também pode introduzir algum erro nas estimativas da licitação selada, especialmente pela a ausência de garantia na satisfação das condições iniciais.

$9 \quad$ Conforme descrito no capítulo 4. 



\section{Conclusão}

Neste trabalho, nós comparamos duas formas de licitações presentes na Bolsa Eletrônica de Compras do Estado de São Paulo. A precisão na descrição dos bens transacionados e a publicidade da identidade dos vencedores das licitações nos possibilitou fazer essa análise. Encontramos um preço inferior de aproximadamente 3\% no preço da licitação selada em relação ao da licitação aberta na compra do açúcar refinado. Dessa forma, o governo do Estado de São Paulo poderia economizar essa quantia se usasse o formato selado para todas as suas licitações. O Apêndice B gera evidência de que essa diferença não ocorre somente para o açúcar e provém os mesmos exercícios empíricos para o detergente transacionado na BEC no mesmo período.

Recuperando a propensão a pagar dos licitantes com econometria estrutural, nós encontramos que um modelo com assimetria e aversão ao risco pode explicar a diferença entre os formatos, apesar de não podermos descartar conluio ou efeitos gerados pela via eletrônica como jump bids.

Nós contemplamos aversão ao risco em nosso modelo de uma forma simples, mas pouco robusta. Nosso parâmetro de aversão ao risco não foi estimado e pode captar o efeito do desconhecimento do número de participantes na licitação em questão. Uma estimativa precisa do grau de aversão ao risco dos licitantes neste modelo, utilizando o benefício dos dois formatos de licitação, é deixado para pesquisa futura. Deixamos para pesquisa futura também, a elaboração de novas formas de licitação ainda mais vantajosas para o Estado e suas implicações para o bem-estar da sociedade. 



\section{Referências}

ABADIE, A.; IMBENS, G. W. Matching on the estimated propensity score. NBER Working Paper, n. w15301, 2009.

ATHEY, S.; HAILE, P. A. Chapter 60 nonparametric approaches to auctions. In: HECKMAN, J. J.; LEAMER, E. E. (Ed.). [S.l.]: Elsevier, 2007, (Handbook of Econometrics, v. 6, Part A). p. $3847-3965$.

ATHEY, S.; LEVIN, J.; SEIRA, E. Comparing open and sealed bid auctions: Evidence from timber auctions. The Quartely Journal of Economics, v. 126, n. 1, p. 207-257, 2011.

BAJARI, P. Comparing competition and collusion: A numerical approach. Economic Theory, v. 18, 2001.

BRENDSTRUP, B.; PAARSCH, H. J. Identification and estimation in sequential, asymmetric, english auctions. Journal of Econometrics, v. 134, 2006.

CAMPO, S. Risk aversion and asymmetry in procurement auctions: Identification, estimation and application to construction procurements. Journal of Econometrics, v. 168, p. 96-107, 2012.

CAMPO, S. et al. Semiparametric estimation of first-price auctions with risk-averse bidders. Review of Economics Studies, v. 78, 2011.

GUERRE, E.; PERRIGNE, I.; VUONG, Q. Optimal nonparametric estimation of first-price auctions. Econometrica, v. 68, n. 3, p. 525-574, May 2000.

HAILE, P. A.; TAMER, E. Inference with an incomplete model of english auctions. Journal of Political Economy, v. 111, n. 1, p. 1-52, 2003.

HANSEN, R. G. Empirical testing of auction theory. In: Papers and Proceedings of the Ninety Seventh Annual Meeting of the American Economic Association. [S.l.: s.n.], 1985. v. 75, n. 2 , p. $156-159$.

HUBBARD, T. P.; PAARSCH, H. J. Chapter 2 - on the numerical solution of equilibria in auction models with asymmetries within the private-values paradigm. In: SCHMEDDERS, K.; JUDD, K. L. (Ed.). Handbook of Computational Economics Vol. 3. [S.l.]: Elsevier, 2014, (Handbook of Computational Economics, v. 3). p. 37 - 115.

KRASNOKUTSKAYA, E. Identification and estimation of auction models with unobserved heterogeneity. The Review of Economic Studies, v. 78, n. 1, p. 293-327, 2011.

LU, J.; PERRIGNE, I. Estimating risk aversion from ascending and sealed-bid auctions: the case of timber auction data. Journal of Applied Econometrics, v. 23, n. 7, p. 871-896, 2008 .

MASKIN, E.; RILEY, J. Asymmetric auctions. The Review of Economic Studies, v. 67, n. 3, p. 413-438, July 2000.

MASKIN, E.; RILEY, J. Uniqueness of equilibrium in sealed high-bid auctions. Games and Economic Behavior, v. 45, p. 395-409, 2003. 
MCAFEE, R. P.; MCMILLAN, J. Auctions and bidding. Journal of Economic Literature, American Economic Association, v. 25, n. 2, p. pp. 699-738, 1987.

MEAD, W. J. Natural resource disposal policy - oral auction versus sealed bid. Natural Resources Journal, v. 7, p. 194-224, April 1967.

MILGROM, P. R.; WEBER, R. J. A theory of auctions and competitive bidding. Econometrica, v. 50, n. 5, p. 1089-1122, September 1982.

PAARSCH, H. J. Deciding between the common and private value paradigms in empirical models of auctions. Journal of Econometrics, v. 51, p. 191-215, 1992.

RILEY, J. G.; SAMUELSON, W. F. Optimal auctions. The American Economic Review, v. 71, n. 3, p. 381-392, June 1981.

ROSENBAUM, P. R.; RUBIN, D. B. The central role of the propensity score in observational studies for causal effects. Biometrika, v. 70, n. 1, p. 41-55, 1983.

VICKREY, W. Counterspeculation, auctions, and competitive sealed tender. The Journal of Finance, v. 16, n. 1, p. 8-37, March 1961. 


\section{Apêndice $A$}

Este apêndice contém algumas tabelas que foram retiradas do corpo principal do texto para facilitar a leitura.

Tabela 8 - Formato de licitação por município

(Continua)

\begin{tabular}{|c|c|c|c|c|}
\hline Código & Nome do Município & Aberto & Selado & Total \\
\hline Mun $_{1}$ & Américo Brasiliense & 3 & 7 & 10 \\
\hline Mun $_{2}$ & Andradina & 5 & 0 & 5 \\
\hline Mun $_{3}$ & Apiaí & 1 & 0 & 1 \\
\hline Mun $_{4}$ & Araçatuba & 17 & 26 & 43 \\
\hline Mun $_{5}$ & Araraquara & 6 & 40 & 46 \\
\hline Mun $_{6}$ & Assis & 2 & 1 & 3 \\
\hline Mun $_{7}$ & Avaré & 0 & 4 & 4 \\
\hline Mun $_{8}$ & Barueri & 8 & 9 & 17 \\
\hline Mun $_{9}$ & Bauru & 34 & 32 & 66 \\
\hline Mun $_{10}$ & Bebedouro & 13 & 0 & 13 \\
\hline Mun $_{11}$ & Birigui & 2 & 2 & 4 \\
\hline Mun $_{12}$ & Botucatu & 1 & 1 & 2 \\
\hline Mun $_{13}$ & Bragança Paulista & 1 & 30 & 31 \\
\hline Mun $_{14}$ & Caieiras & 0 & 4 & 4 \\
\hline Mun $_{15}$ & Campinas & 28 & 90 & 118 \\
\hline Mun $_{16}$ & Capivari & 3 & 1 & 4 \\
\hline Mun $_{17}$ & Caraguatatuba & 16 & 0 & 16 \\
\hline Mun $_{18}$ & Carapicuíba & 11 & 3 & 14 \\
\hline Mun $_{19}$ & Casa Branca & 1 & 0 & 1 \\
\hline Mun $_{20}$ & Catanduva & 2 & 1 & 3 \\
\hline Mun $_{21}$ & Cruzeiro & 2 & 0 & 2 \\
\hline Mun $_{22}$ & Diadema & 23 & 9 & 32 \\
\hline Mun $_{23}$ & Embu & 15 & 0 & 15 \\
\hline Mun $_{24}$ & Fernandópolis & 2 & 3 & 5 \\
\hline $\operatorname{Mun}_{25}$ & Ferraz de Vasconcelos & 2 & 2 & 4 \\
\hline Mun $_{26}$ & Franco da Rocha & 27 & 13 & 40 \\
\hline Mun $_{27}$ & Guaratinguetá & 9 & 0 & 9 \\
\hline Mun $_{28}$ & Guarujá & 1 & 19 & 20 \\
\hline Mun $_{29}$ & Guarulhos & 24 & 32 & 56 \\
\hline Mun $_{30}$ & Iaras & 0 & 8 & 8 \\
\hline Mun $_{31}$ & Iperó & 1 & 0 & 1 \\
\hline Mun $_{32}$ & Itanhaém & 3 & 6 & 9 \\
\hline Mun $_{33}$ & Itapecerica da Serra & 11 & 0 & 11 \\
\hline Mun $_{34}$ & Itapeva & 1 & 0 & 1 \\
\hline Mun $_{35}$ & Itapevi & 0 & 4 & 4 \\
\hline Mun $_{36}$ & Itaquaquecetuba & 15 & 3 & 18 \\
\hline Mun $_{37}$ & Itu & 3 & 12 & 15 \\
\hline
\end{tabular}


Tabela 8 - Formato da licitação por município (Continuação)

\begin{tabular}{|c|c|c|c|c|}
\hline Código & Nome do Município & Aberto & Selado & Total \\
\hline $\operatorname{Mun}_{38}$ & Jacareí & 21 & 3 & 24 \\
\hline Mun $_{39}$ & Jacupiranga & 10 & 0 & 10 \\
\hline Mun $_{40}$ & Jales & 2 & 0 & 2 \\
\hline Mun $_{41}$ & Jundiaí & 5 & 14 & 19 \\
\hline Mun $_{42}$ & Limeira & 2 & 6 & 8 \\
\hline Mun $_{43}$ & Lins & 7 & 2 & 9 \\
\hline Mun $_{44}$ & Marília & 29 & 28 & 57 \\
\hline Mun $_{45}$ & Mauá & 38 & 1 & 39 \\
\hline Mun $_{46}$ & Miracatu & 1 & 0 & 1 \\
\hline Mun $_{47}$ & Mogi das Cruzes & 13 & 22 & 35 \\
\hline Mun $_{48}$ & Mogi Guaçu & 10 & 7 & 17 \\
\hline Mun $_{49}$ & Mogi Morim & 11 & 0 & 11 \\
\hline Mun $_{50}$ & Nova Odessa & 0 & 6 & 6 \\
\hline Mun $_{51}$ & Osasco & 36 & 42 & 78 \\
\hline Mun $_{52}$ & Ourinhos & 2 & 4 & 6 \\
\hline Mun $_{53}$ & Penápolis & 3 & 1 & 4 \\
\hline Mun $_{54}$ & Pindamonhagaba & 5 & 3 & 8 \\
\hline Mun $_{55}$ & Piracicaba & 7 & 1 & 8 \\
\hline Mun $_{56}$ & Piraju & 0 & 1 & 1 \\
\hline Mun $_{57}$ & Potim & 2 & 0 & 2 \\
\hline Mun $_{58}$ & Praia Grande & 35 & 4 & 39 \\
\hline Mun $_{59}$ & Presidente Prudente & 6 & 0 & 6 \\
\hline Mun $_{60}$ & Presidente Venceslau & 0 & 7 & 7 \\
\hline Mun $_{61}$ & Promissão & 0 & 1 & 1 \\
\hline Mun $_{62}$ & Registro & 13 & 6 & 19 \\
\hline Mun $_{63}$ & Ribeirão Pires & 13 & 11 & 24 \\
\hline Mun $_{64}$ & Rio Claro & 3 & 14 & 17 \\
\hline Mun $_{65}$ & Santo André & 13 & 60 & 73 \\
\hline $\operatorname{Mun}_{66}$ & Santos & 21 & 19 & 40 \\
\hline Mun $_{67}$ & São Bernardo do Campo & 28 & 25 & 53 \\
\hline Mun $_{68}$ & São Carlos & 15 & 0 & 15 \\
\hline Mun $_{69}$ & São João da Boa Vista & 24 & 1 & 25 \\
\hline Mun $_{70}$ & São José do Rio Preto & 32 & 26 & 58 \\
\hline $\operatorname{Mun}_{71}$ & São José dos Campos & 63 & 14 & 77 \\
\hline $\operatorname{Mun}_{72}$ & São Paulo & 694 & 924 & 1.618 \\
\hline $\operatorname{Mun}_{73}$ & São Roque & 2 & 0 & 2 \\
\hline $\operatorname{Mun}_{74}$ & São Sebastião & 11 & 0 & 11 \\
\hline $\operatorname{Mun}_{75}$ & São Vicente & 5 & 0 & 5 \\
\hline Mun $_{76}$ & Sertãozinho & 1 & 8 & 9 \\
\hline Mun $_{77}$ & Sorocaba & 39 & 6 & 45 \\
\hline Mun $_{78}$ & Sumaré & 1 & 1 & 2 \\
\hline Mun $_{79}$ & Suzano & 26 & 6 & 32 \\
\hline Mun $_{80}$ & Taboão da Serra & 8 & 3 & 11 \\
\hline Mun $_{81}$ & Taubaté & 19 & 18 & 37 \\
\hline
\end{tabular}


Tabela 8 - Formato da licitação por município

(Continuação)

\begin{tabular}{llccc}
\hline Código & Nome do Município & Aberto & Selado & Total \\
\hline Mun $_{82}$ & Tupã & 3 & 8 & 11 \\
Mun $_{83}$ & Votorantim & 2 & 0 & 2 \\
Mun $_{84}$ & Votuporanga & 3 & 0 & 3 \\
\hline \multicolumn{2}{c}{ Total } & 1.577 & 1.665 & 3.242 \\
\hline
\end{tabular}

Fonte: BEC.

Nota: Elaboração Própria.

Tabela 9 - Comparação dos controles após o Matching (Continua)

\begin{tabular}{|c|c|c|c|c|}
\hline \multirow[b]{2}{*}{ Controles } & \multicolumn{2}{|c|}{ Médias } & \multicolumn{2}{|c|}{$\begin{array}{c}\text { Teste t para diferença de } \\
\text { médias }\end{array}$} \\
\hline & Selado & Aberto & t-estat & $\mathrm{p}$-valor \\
\hline ln (quantidade) & 5,290 & 5,290 & $-0,01$ & 0,995 \\
\hline$N_{1}$ & 1,410 & 1,396 & 0,82 & 0,410 \\
\hline$N_{2}$ & 3,715 & 3,721 & $-0,17$ & 0,865 \\
\hline$N_{3}$ & 13,594 & 13,665 & $-0,55$ & 0,585 \\
\hline$t_{2009}$ & 0,295 & 0,293 & 0,16 & 0,873 \\
\hline$t_{2010}$ & 0,344 & 0,350 & $-0,41$ & 0,681 \\
\hline$t_{2011}$ & 0,137 & 0,133 & 0,28 & 0,778 \\
\hline$m_{3}$ & 0,104 & 0,095 & 0,86 & 0,392 \\
\hline$m_{4}$ & 0,085 & 0,095 & $-1,07$ & 0,284 \\
\hline$m_{5}$ & 0,112 & 0,126 & $-1,22$ & 0,221 \\
\hline$m_{6}$ & 0,103 & 0,102 & 0,14 & 0,889 \\
\hline$m_{7}$ & 0,076 & 0,073 & 0,32 & 0,752 \\
\hline$m_{8}$ & 0,099 & 0,099 & 0,07 & 0,945 \\
\hline$m_{9}$ & 0,079 & 0,081 & $-0,15$ & 0,880 \\
\hline$m_{10}$ & 0,066 & 0,057 & 1,08 & 0,280 \\
\hline$m_{11}$ & 0,112 & 0,111 & 0,05 & 0,963 \\
\hline$m_{12}$ & 0,094 & 0,101 & $-0,60$ & 0,552 \\
\hline Mun $_{4}$ & 0,016 & 0,015 & 0,19 & 0,850 \\
\hline Mun $_{5}$ & 0,025 & 0,035 & $-1,72$ & 0,085 \\
\hline Mun $_{6}$ & 0,001 & 0,001 & $-0,58$ & 0,564 \\
\hline Mun $_{8}$ & 0,006 & 0,003 & 0,92 & 0,357 \\
\hline Mun $_{9}$ & 0,020 & 0,026 & $-1,28$ & 0,202 \\
\hline Mun $_{11}$ & 0,001 & 0,000 & 1,41 & 0,157 \\
\hline Mun $_{12}$ & 0,001 & 0,001 & $-0,58$ & 0,564 \\
\hline
\end{tabular}


Tabela 9 - Comparação dos Controles após o Matching

(Continuação)

\begin{tabular}{|c|c|c|c|c|}
\hline \multirow[b]{2}{*}{ Controles } & \multicolumn{2}{|c|}{ Médias } & \multicolumn{2}{|c|}{$\begin{array}{c}\text { Teste t para diferença de } \\
\text { médias }\end{array}$} \\
\hline & Selado & Aberto & t-estat & p-valor \\
\hline Mun $_{13}$ & 0,018 & 0,013 & 1,32 & 0,186 \\
\hline Mun $_{15}$ & 0,055 & 0,053 & 0,28 & 0,777 \\
\hline Mun $_{16}$ & 0,001 & 0,001 & $-0,17$ & 0,868 \\
\hline Mun $_{18}$ & 0,002 & 0,002 & $-0,26$ & 0,796 \\
\hline Mun $_{20}$ & 0,001 & 0,001 & 0,00 & 1,000 \\
\hline Mun $_{22}$ & 0,006 & 0,006 & $-0,36$ & 0,720 \\
\hline Mun $_{24}$ & 0,002 & 0,002 & 0,00 & 1,000 \\
\hline Mun $_{25}$ & 0,001 & 0,000 & 0,82 & 0,414 \\
\hline Mun $_{26}$ & 0,008 & 0,011 & $-0,86$ & 0,390 \\
\hline Mun $_{28}$ & 0,012 & 0,011 & 0,05 & 0,956 \\
\hline Mun $_{29}$ & 0,020 & 0,023 & $-0,73$ & 0,463 \\
\hline Mun $_{32}$ & 0,004 & 0,004 & $-0,28$ & 0,781 \\
\hline Mun $_{36}$ & 0,002 & 0,002 & 0,00 & 1,000 \\
\hline Mun $_{37}$ & 0,007 & 0,003 & 1,61 & 0,108 \\
\hline Mun $_{38}$ & 0,002 & 0,001 & 0,45 & 0,655 \\
\hline Mun $_{41}$ & 0,009 & 0,008 & 0,16 & 0,872 \\
\hline Mun $_{42}$ & 0,004 & 0,006 & $-0,78$ & 0,438 \\
\hline Mun $_{43}$ & 0,001 & 0,001 & 0,17 & 0,862 \\
\hline Mun $_{44}$ & 0,017 & 0,013 & 1,05 & 0,296 \\
\hline Mun $_{45}$ & 0,001 & 0,001 & $-0,58$ & 0,564 \\
\hline Mun $_{47}$ & 0,014 & 0,012 & 0,47 & 0,637 \\
\hline Mun $_{48}$ & 0,004 & 0,005 & $-0,42$ & 0,673 \\
\hline Mun $_{51}$ & 0,026 & 0,022 & 0,72 & 0,473 \\
\hline Mun $_{52}$ & 0,002 & 0,002 & 0,00 & 1,000 \\
\hline Mun $_{53}$ & 0,001 & 0,001 & 0,00 & 1,000 \\
\hline Mun $_{54}$ & 0,002 & 0,001 & 0,62 & 0,537 \\
\hline Mun $_{55}$ & 0,001 & 0,000 & 0,26 & 0,796 \\
\hline Mun $_{58}$ & 0,002 & 0,001 & 0,66 & 0,508 \\
\hline Mun $_{62}$ & 0,004 & 0,004 & 0,00 & 1,000 \\
\hline Mun $_{63}$ & 0,007 & 0,006 & 0,33 & 0,740 \\
\hline Mun $_{64}$ & 0,009 & 0,009 & $-0,17$ & 0,864 \\
\hline Mun $_{65}$ & 0,037 & 0,032 & 0,82 & 0,413 \\
\hline Mun $_{66}$ & 0,012 & 0,013 & $-0,40$ & 0,693 \\
\hline Mun $_{67}$ & 0,015 & 0,013 & 0,45 & 0,650 \\
\hline Mun $_{69}$ & 0,001 & 0,000 & 1,00 & 0,317 \\
\hline$M_{u n}$ & 0,016 & 0,022 & $-1,28$ & 0,200 \\
\hline Mun $_{71}$ & 0,009 & 0,006 & 0,88 & 0,382 \\
\hline Mun $_{72}$ & 0,567 & 0,575 & $-0,46$ & 0,644 \\
\hline
\end{tabular}


Tabela 9 - Comparação dos Controles após o Matching

(Continuação)

\begin{tabular}{|c|c|c|c|c|}
\hline \multirow[b]{2}{*}{ Controles } & \multicolumn{2}{|c|}{ Médias } & \multicolumn{2}{|c|}{$\begin{array}{c}\text { Teste t para diferença de } \\
\text { médias }\end{array}$} \\
\hline & Selado & Aberto & t-estat & $\mathrm{p}$-valor \\
\hline Mun $_{76}$ & 0,005 & 0,001 & 2,19 & 0,029 \\
\hline Mun $_{77}$ & 0,004 & 0,002 & 0,63 & 0,527 \\
\hline Mun $_{78}$ & 0,001 & 0,001 & $-0,22$ & 0,827 \\
\hline Mun $_{79}$ & 0,004 & 0,004 & $-0,07$ & 0,943 \\
\hline Mun $_{80}$ & 0,002 & 0,002 & 0,00 & 1,000 \\
\hline Mun $_{81}$ & 0,011 & 0,009 & 0,56 & 0,579 \\
\hline Mun $_{82}$ & 0,005 & 0,006 & $-0,40$ & 0,691 \\
\hline
\end{tabular}

Fonte: BEC.

Nota: Elaboração Própria. Estatísticas t calculadas de uma regressão de cada controle na dummy selado. Essa regressão foi feita ponderando as observações pelo número de vezes que ela foi pareada. $\ln$ (quantidade) é o logaritmo da quantidade vendida. $N_{1}, N_{2}$ e $N_{3}$ indicam o número de licitantes do tipo Grande, Médio e Pequeno respectivamente. As demais variáveis são variáveis binárias onde o índice $t$ indica uma dummy para o ano assinalado, $m$ indica uma dummy para o mês assinalado e Mun uma dummy para o município.

Tabela 10 - Agregação dos municípios para estimação estrutural (Continua)

\begin{tabular}{ccc}
\hline Agregação & Região Administrativa & Nome do Munícipio \\
\hline Centro & Bauru & Bauru \\
Centro & Bauru & Lins \\
Centro & Bauru & Promissão \\
Centro & Central & Américo Brasiliense \\
Centro & Central & Araraquara \\
Centro & Central & São Carlos \\
Centro & Marília & Assis \\
Centro & Marília & Marília \\
Centro & Marília & Ourinhos \\
Centro & Maŕlia & Tupã \\
Centro & Ribeirão Preto & Ribeirão Preto \\
Centro & Ribeirão Preto & Sertãozinho \\
Grande São Paulo & Grande São Paulo & Barueri \\
Grande São Paulo & Grande São Paulo & Caieiras \\
Grande São Paulo & Grande São Paulo & Carapicuiba \\
Grande São Paulo & Grande São Paulo & Diadema \\
Grande São Paulo & Grande São Paulo & Embu \\
Grande São Paulo & Grande São Paulo & Ferraz de Vasconcelos \\
Grande São Paulo & Grande São Paulo & Franco da Rocha
\end{tabular}


Tabela 10 - Agregação dos municípios para estimação estrutural

(Continuação)

\begin{tabular}{|c|c|c|}
\hline Agregação & Região Administrativa & Nome do Munícipio \\
\hline Grande São Paulo & Grande São Paulo & Guarulhos \\
\hline Grande São Paulo & Grande São Paulo & Itapecerica da Serra \\
\hline Grande São Paulo & Grande São Paulo & Itapevi \\
\hline Grande São Paulo & Grande São Paulo & Itaquaquecetuba \\
\hline Grande São Paulo & Grande São Paulo & Mauá \\
\hline Grande São Paulo & Grande São Paulo & Mogi das Cruzes \\
\hline Grande São Paulo & Grande São Paulo & Osasco \\
\hline Grande São Paulo & Grande São Paulo & Santo André \\
\hline Grande São Paulo & Grande São Paulo & São Bernardo do Campo \\
\hline Grande São Paulo & Grande São Paulo & São Paulo \\
\hline Grande São Paulo & Grande São Paulo & Suzano \\
\hline Grande São Paulo & Grande São Paulo & Taboão da Serra \\
\hline Litoral & Registro & Jacupiranga \\
\hline Litoral & Registro & Miracatu \\
\hline Litoral & Registro & Registro \\
\hline Litoral & Santos & Guarujá \\
\hline Litoral & Santos & Itanhaem \\
\hline Litoral & Santos & Praia Grande \\
\hline Litoral & Santos & Santos \\
\hline Litoral & Santos & São Vicente \\
\hline Litoral & São José dos Campos & Caraguatatuba \\
\hline Litoral & São José dos Campos & Cruzeiro \\
\hline Litoral & São José dos Campos & Guaratinguetá \\
\hline Litoral & São José dos Campos & Jacareí \\
\hline Litoral & São José dos Campos & Pindamonhangaba \\
\hline Litoral & São José dos Campos & Potim \\
\hline Litoral & São José dos Campos & São José dos Campos \\
\hline Litoral & São José dos Campos & São Sebastião \\
\hline Litoral & São José dos Campos & Taubaté \\
\hline Norte & Araçatuba & Andradina \\
\hline Norte & Araçatuba & Araçatuba \\
\hline Norte & Araçatuba & Birigui \\
\hline Norte & Araçatuba & Penápolis \\
\hline Norte & Barretos & Bebedouro \\
\hline Norte & Presidente Prudente & Presidente Prudente \\
\hline Norte & Presidente Prudente & Presidente Venceslau \\
\hline Norte & Sao José do Rio Preto & Catanduva \\
\hline Norte & Sao José do Rio Preto & Fernandópolis \\
\hline Norte & Sao José do Rio Preto & Jales \\
\hline Norte & Sao José do Rio Preto & Sao José do Rio Preto \\
\hline Norte & Sao José do Rio Preto & Votuporanga \\
\hline Sul & Campinas & Bragança Paulista \\
\hline Sul & Campinas & Campinas \\
\hline Sul & Campinas & Capivari \\
\hline
\end{tabular}


Tabela 10 - Agregação dos municípios para estimação estrutural (Continuação)

\begin{tabular}{ccc}
\hline Agregação & Região Administrativa & Nome do Munícipio \\
\hline Sul & Campinas & Casa Branca \\
Sul & Campinas & Jundiaí \\
Sul & Campinas & Limeira \\
Sul & Campinas & Mogi Guaçu \\
Sul & Campinas & Mogi Mirim \\
Sul & Campinas & Nova Odessa \\
Sul & Campinas & Piracicaba \\
Sul & Campinas & Rio Claro \\
Sul & Campinas & Sao João da Boa Vista \\
Sul & Campinas & Sumaré \\
Sul & Sorocaba & Apiaí \\
Sul & Sorocaba & Avaré \\
Sul & Sorocaba & Botucatu \\
Sul & Sorocaba & Iaras \\
Sul & Sorocaba & Iperó \\
Sul & Sorocaba & Itapeva \\
Sul & Sorocaba & Itu \\
Sul & Sorocaba & Piraju \\
Sul & Sorocaba & São Roque \\
Sul & Sorocaba & Sorocaba \\
Sul & Sorocaba & Votorantim \\
\hline
\end{tabular}

Fonte: BEC.

Nota: Elaboração Própria. 
Tabela 11 - Comparação de preço entre formatos de licitação -

Nova classificação dos licitantes

\begin{tabular}{|c|c|c|c|c|}
\hline & \multicolumn{4}{|c|}{$\ln ($ preço) } \\
\hline $\begin{array}{c}\text { Variáveis } \\
\text { Independentes }\end{array}$ & (1) & $(2)$ & $(3)$ & (4) \\
\hline \multirow[t]{2}{*}{ selado } & $-0,0449 * * *$ & $-0,0475^{* * *}$ & $-0,0467 * * *$ & $-0,0280 * * *$ \\
\hline & $(0,0042)$ & $(0,0042)$ & $(0,0041)$ & $(0,0042)$ \\
\hline \multirow[t]{2}{*}{ ln (quantidade) } & $-0,0251^{* * *}$ & $-0,0250^{* * *}$ & $-0,0259 * * *$ & $-0,0247^{* * *}$ \\
\hline & $(0,0019)$ & $(0,0018)$ & $(0,0018)$ & $(0,0018)$ \\
\hline \multirow[t]{2}{*}{$N_{1}$} & 0,0029 & $0,0221^{* * *}$ & $-0,0109$ & $-0,0150^{*}$ \\
\hline & $(0,0067)$ & $(0,0070)$ & $(0,0085)$ & $(0,0080)$ \\
\hline \multirow[t]{2}{*}{$N_{2}$} & $-0,0051^{* * *}$ & $-0,0115^{* * *}$ & $-0,0083^{* * *}$ & $-0,0102^{* * *}$ \\
\hline & $(0,0013)$ & $(0,0015)$ & $(0,0018)$ & $(0,0017)$ \\
\hline \multirow[t]{2}{*}{$N_{3}$} & $-0,0006$ & 0,0007 & 0,0011 & 0,0009 \\
\hline & $(0,0006)$ & $(0,0006)$ & $(0,0008)$ & $(0,0008)$ \\
\hline $\begin{array}{l}\text { dummies } \\
\text { de ano }\end{array}$ & Não & Sim & Sim & Sim \\
\hline $\begin{array}{l}\text { dummies } \\
\text { de mês }\end{array}$ & Não & Não & Sim & Sim \\
\hline $\begin{array}{c}\text { dummies } \\
\text { de município }\end{array}$ & Não & Não & Não & Sim \\
\hline Observações & 3.242 & 3.242 & 3.242 & 3.242 \\
\hline $\bar{R}^{2}$ & 0,0952 & 0,1282 & 0,1785 & 0,2860 \\
\hline
\end{tabular}

Fonte: BEC

Notas: Elaboração Própria. Resultados da equação 6.1. Licitantes do Tipo 1 foram classificados como aqueles venceram $17 \%$ ou mais das licitações nos últimos 5 meses. Licitantes do Tipo 2 foram classificados como aqueles venceram entre $3 \%$ e $17 \%$ das licitações nos últimos 5 meses. Licitantes do Tipo 3 foram classificados como aqueles venceram menos de $3 \%$ das licitações nos últimos 5 meses. Erros padrão robustos entre parêntesis. ${ }^{* * *}$ p-valor $<0,01,{ }^{* *}$ p-valor $<0,05,{ }^{*}$ p-valor $<0,1$ 

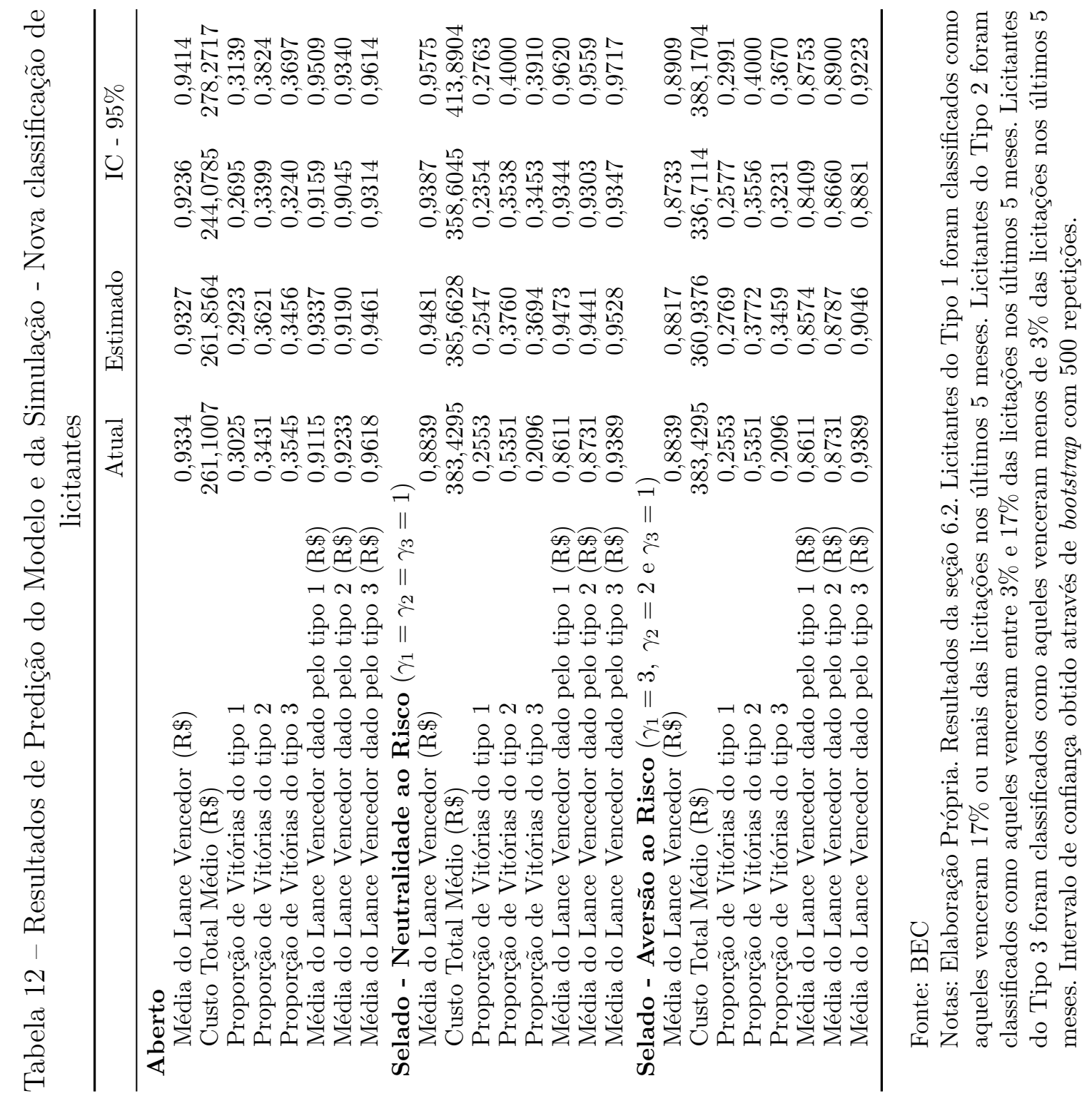



\section{Apêndice B}

Neste apêndice, propomos refazer alguns dos exercícios econométricos citados no texto com as vendas de detergente transacionados na BEC. O intuito desse apêndice é gerar evidência adicional de que a licitação selada gera um custo menor para o Estado em relação à licitação aberta.

Propomos analisar de forma suscinta as compras de detergente 500ml em caixas contendo 24 unidades cada no mesmo período de 2008 a 2011. ${ }^{1}$ A Tabela 13 descreve os dados das transações de detergente que usamos. Nota-se que a dispersão de preços é muito maior neste bem que no caso do acçúcar discutido no texto principal. Também se observa que a licitação selada apresenta preço unitário menor que a licitação aberta.

A Tabela 14 mostram as regressões segundo a seção 6.1. Encontramos um impacto de 3,49\% a menos no preço na licitação selada em comparação com a aberta.

A Tabela 15 mostra as estimativas feitas por Propensity score matching. Este exercício é um pouco diferente do descrito do texto principal. Somente utilizamos no pareamento observações com propensity score entre 0.05 e 0.95 . Também utilizamos 5 observações no pareamento. Desta forma, obtemos um valor da redução de custo em $4 \%$ em favor da licitação selada.

Esses resultados indicam que a licitação selada pode ter um impacto de redução de custo em vários bens e não apenas no açúcar refinado descrito na parte principal deste texto.

A Tabela 16 mostra os resultados das estimações e simulações descritas na seção 6.2 para o detergente. Novamente, nossas simulações conseguem se aproximar muito bem dos dados observados. Nota-se que aversão ao risco não foi necessária para explicar o comportamento dos agentes, pois a simulação sob neutralidade ao risco se aproxima muito

1 A descrição detalhada do bem pode ser vista a seguir exatamente como se encontra no site da BEC: Cód. item: 1320530 Detergente Liquido; Principio Ativo Linear Alquil Benzeno,sulfonato de Sodio,teor Minimo de 6\%; Composicao Basica Tensoativos:anionicos,nao Ionicos,coadjuvante; Preservantes,sequestrante,espessante,fragancias e Outras Substancias Quimicas Permitidas; Valor do Ph Entre 6,0 e 8,0,solucao a 1\% P/p; Composicao Aromatica Neutro,incolor,com Validade 3 Anos; Acondicionado de Forma Adequada; Produto Sujeito a Verificacao No Ato Da Entrega; Aos

Procedimentos Adm. Determinados Pela Anvisa; 


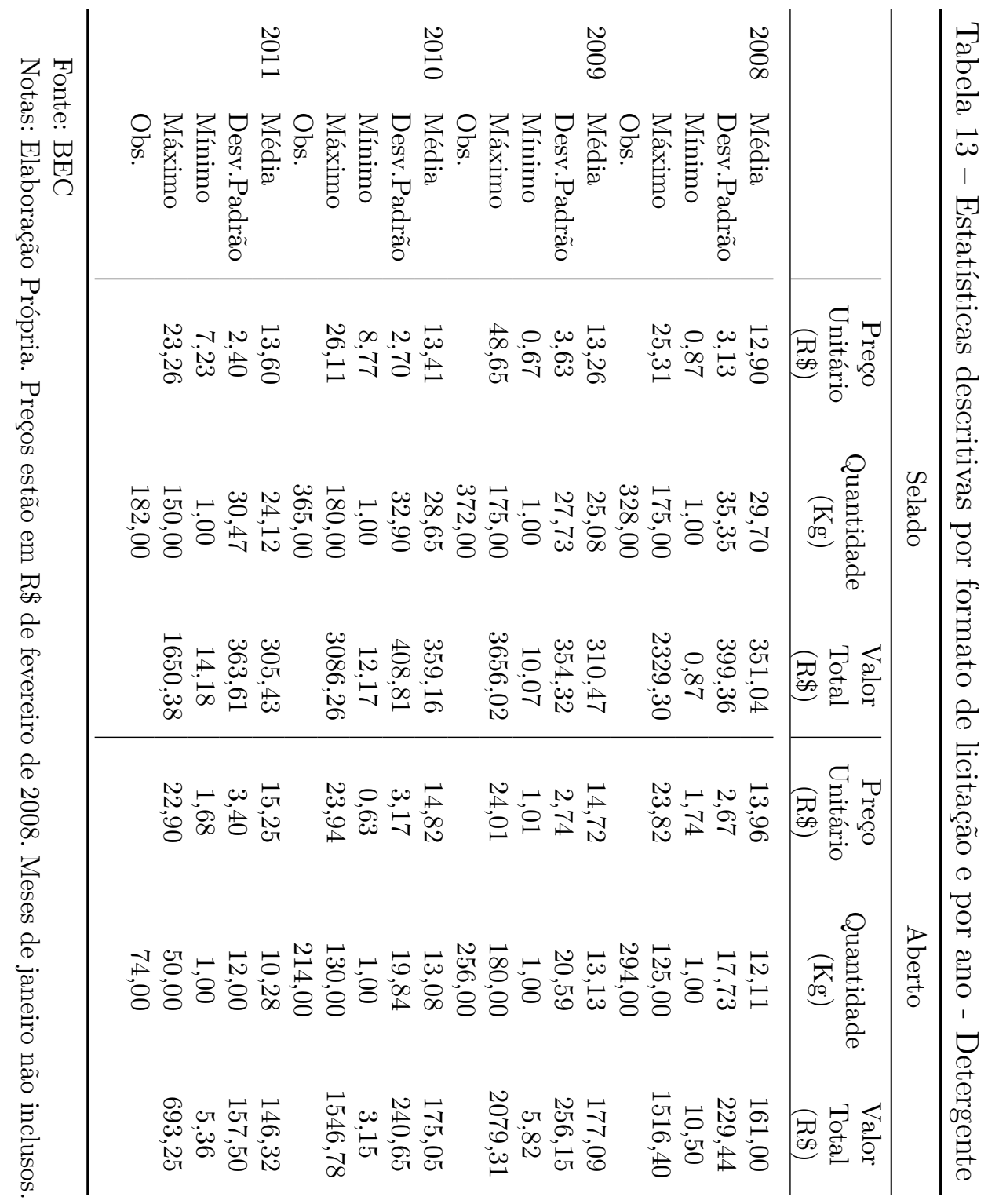


bem dos dados observados.

Tabela 14 - Comparação de preço entre formatos de licitação -

Detergente

\begin{tabular}{ccccc}
\hline & \multicolumn{5}{c}{$\ln$ (preço) } \\
\hline Variáveis & $(1)$ & $(2)$ & $(3)$ & $(4)$ \\
Independentes & & & & \\
selado & $-0,0400^{* * *}$ & $-0,0452^{* * *}$ & $-0,0462^{* * *}$ & $-0,0349^{* *}$ \\
& $(0,0128)$ & $(0,0131)$ & $(0,0130)$ & $(0,0140)$ \\
ln (quantidade) & $-0,0597^{* * *}$ & $-0,0593^{* * *}$ & $-0,0600^{* * *}$ & $-0,0560^{* * *}$ \\
& $(0,0045)$ & $(0,0045)$ & $(0,0044)$ & $(0,0054)$ \\
$N_{1}$ & $-0,0095$ & $-0,0086$ & 0,0029 & $-0,0011$ \\
& $(0,0085)$ & $(0,0085)$ & $(0,0124)$ & $(0,0126)$ \\
$N_{2}$ & $-0,0010$ & 0,0012 & $-0,0040$ & $-0,0047$ \\
& $(0,0042)$ & $(0,0042)$ & $(0,0071)$ & $(0,0072)$ \\
$N_{3}$ & 0,0013 & $0,0044^{* *}$ & 0,0040 & 0,0041 \\
& $(0,0018)$ & $(0,0019)$ & $(0,0025)$ & $(0,0027)$ \\
dummies & Não & Sim & Sim & Sim \\
de ano & & & & \\
dummies & Não & Não & Sim & Sim \\
de mês & & & & Sim \\
dummies & Não & Não & Não & \\
de município & & \multirow{2}{*}{2.090} & 2.090 & 2.090 \\
Observações & 2.090 & 0,1136 & 0,1372 \\
$\bar{R}^{2}$ & 0,102 & 0,1102 & 0,116 \\
\hline
\end{tabular}

Fonte: BEC

Notas: Elaboração Própria. Erros padrão robustos entre parêntesis. ${ }^{* * *}$ p-valor $<0,01,{ }^{* *}$ p-valor $<0,05,{ }^{*}$ p-valor $<0,1$ 
Tabela 15 - Efeito do formato de

licitação sobre $\ln ($ Preço $)$ por

Propensity Score Matching -

Detergente

\begin{tabular}{lcc}
\hline & Coeficiente & Erros Padrão \\
\hline$\tau_{p s m}$ & $-0,040^{* * *}$ & 0,0122 \\
Observações & \multicolumn{2}{c}{1781} \\
\hline
\end{tabular}

Fonte: BEC

Notas: Erros padrão robustos calculados segundo Abadie e Imbens (2009). ${ }^{* * *}$ p-valor $<0,01$ 


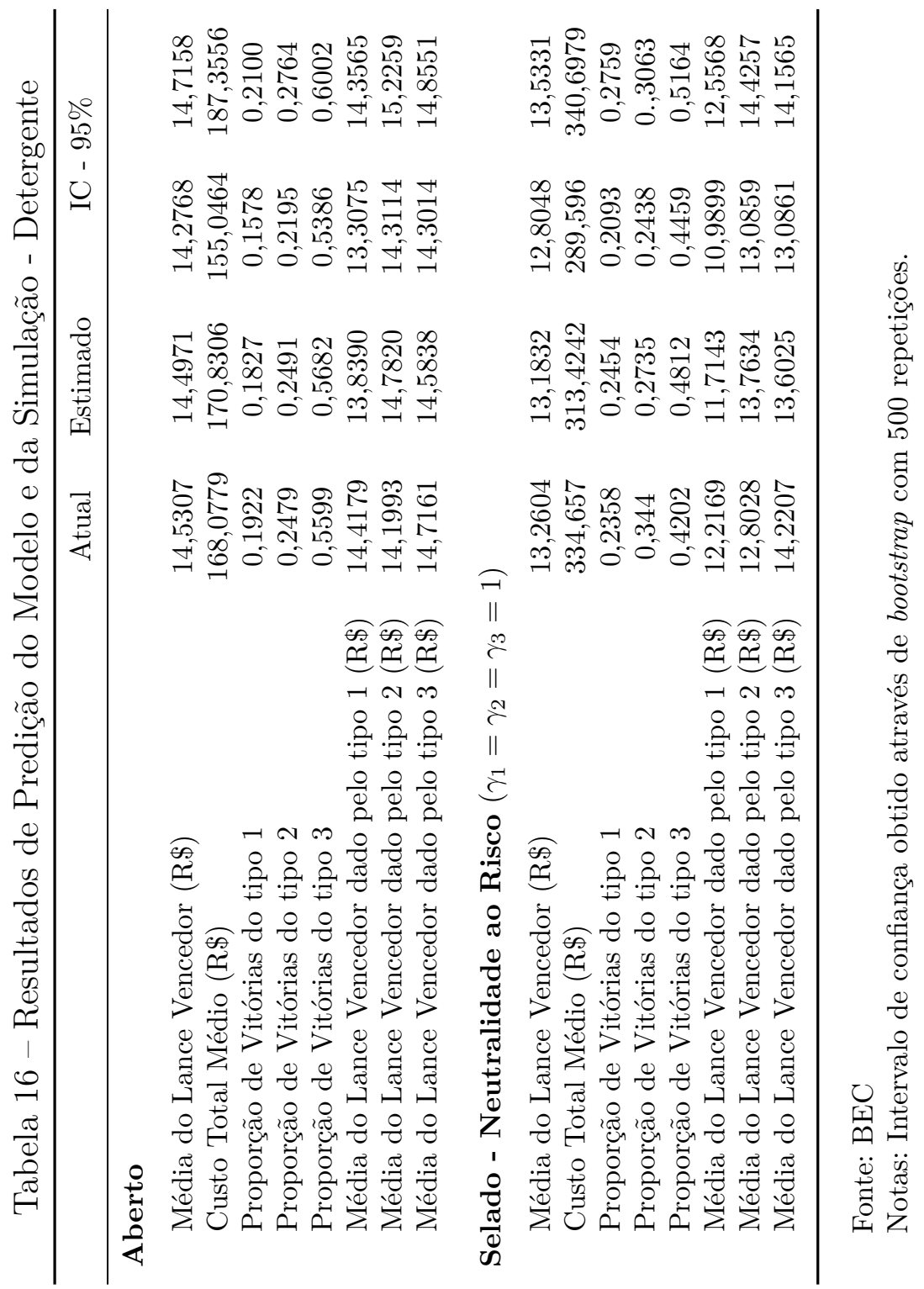

